\title{
Supporting Information for Development of a Performance Evaluation Protocol for Air Sensors Deployed on a Google Street View Car
}

Wilton Mui, Berj Der Boghossian, Ashley Collier-Oxandale, Steven Boddeker, Jason Low, Vasileios Papapostolou, Andrea Polidori

South Coast Air Quality Management District, Diamond Bar, CA 91765, USA

Number of Pages: 26

Number of Figures: 14

Number of Tables: 4

\section{Ground-Based Mobile Platform (GBMP) Infrastructure Details}

The GBMP was contained in a Google Street View (GSV) 2009 Hyundai Santa Fe (exterior dimensions of 184" L x 74" W x 68" H, or $4.7 \mathrm{~m} \mathrm{x} 1.9 \mathrm{~m} \mathrm{x} 1.7 \mathrm{~m}$; maximum cargo capacity of $78.2 \mathrm{ft}^{3}$, or $2.2 \mathrm{~m}^{3}$ ). The rear passenger seats were removed, and the rear cargo area was modified to accommodate GBMP components.

The GBMP contained a suite of reference analyzers measuring a large array of air pollutants, but only the $\mathrm{O}_{3}$ and $\mathrm{PM}_{2.5}$ data was used in this study to compare against the example LCS used to pilot-test this evaluation protocol. Nonetheless, the GMBP is outfitted with many other reference analyzers to accommodate the evaluation of LCS on the market that measure other pollutants. Reference analyzers were housed in steel server racks. Particle-phase analyzers were mounted in one rack in the rear seat row area, while gas-phase analyzers were mounted in two racks in the trunk. Each rack was installed on a vibration-dampening deck. Table S1 summarizes the equipment suite in the GBMP. Comparable reference analyzers between the GBMP and stationary South Coast AQMD Air Monitoring Stations (those measuring the same pollutant and sharing the same US EPA FRM/FEM designation) reported consistent values during drive-by events (Figure 3 and Figure 4 in the main text) and during stationary co-location events (Figure S6).

The power provision system, developed and installed on the GBMP by the Google technical team at the Google facilities and prior to the vehicle delivery to South Coast AQMD, consisted of 5 AGM deep-cycle batteries (12 VDC and $100 \mathrm{Ah}$ each; total of 500Ah) and a $2500 \mathrm{~W}$ pure sine wave inverter and charger (AIMS Power PICOGLF25W12V120AL; 100-120 VAC at $60 \mathrm{~Hz}$ output; $85 \mathrm{~A}$ charging rate). The power system estimated run-time for the GBMP components was greater than 8 hours. All power system components, analyzers, racks, and particle sampling lines were also grounded to the vehicle rack. 
Table S1: Summary of reference analyzers and auxiliary measurement equipment used in the 2009 Hyundai Santa Fe GSV GBMP.

\begin{tabular}{|c|c|c|c|c|}
\hline Manufacturer & Model & Parameter* & $\begin{array}{l}\text { Reporting } \\
\text { Rate, } s\end{array}$ & $\begin{array}{l}\text { US EPA } \\
\text { Designation }^{\dagger}\end{array}$ \\
\hline $\begin{array}{l}\text { GRIMM Aerosol } \\
\text { Technik }\end{array}$ & $11-\mathrm{D}$ & $\mathrm{PM}_{1.0 / 2.5 / 10^{\ddagger}}^{\ddagger}$ & 6 & \\
\hline Teledyne API & T640 & $\mathrm{PM}_{2.5 / 10^{+}}$ & 3 & FEM $\left(\mathrm{PM}_{2.5}\right)$ \\
\hline Teledyne API & $\mathrm{T} 400$ & $\mathrm{O}_{3}$ & 3 & FEM \\
\hline Teledyne API & T500U & $\mathrm{NO}_{2}$ & 3 & FEM \\
\hline Teledyne API & T300 & $\mathrm{CO}$ & 3 & FRM \\
\hline LI-COR & LI-850 & $\mathrm{CO}_{2}$ & 1 & \\
\hline $\begin{array}{l}\text { Aerosol Devices } \\
\text { Inc. (ADI) }\end{array}$ & $\begin{array}{l}\text { MAGIC } \\
\text { Condensation } \\
\text { Particle Counter }\end{array}$ & Particle Count ${ }^{\star}$ & 1 & \\
\hline $\begin{array}{l}\text { Droplet } \\
\text { Measurement } \\
\text { Technologies, Inc. } \\
\text { (DMT) }\end{array}$ & $\begin{array}{l}\text { Photoacoustic } \\
\text { Extinctiometer }\end{array}$ & Black Carbon & 1 & \\
\hline $\begin{array}{l}\text { Extech } \\
\text { Instruments }\end{array}$ & 407119 & Duct Flow Velocity & 1 & \\
\hline Fisherbrand & $\begin{array}{l}\text { Traceable Humidity } \\
\text { Meter }\end{array}$ & Duct $T$ and $R H$ & 1 & \\
\hline
\end{tabular}

*The parameter abbreviations are as follows: Particulate Matter with diameters less than 1.0 or 2.5 or $10 \mu \mathrm{m}\left(\mathrm{PM}_{1.0}\right.$ or $\mathrm{PM}_{2.5}$ or $\mathrm{PM}_{10}$, respectively); Ozone $\left(\mathrm{O}_{3}\right)$; Nitrogen Dioxide $\left(\mathrm{NO}_{2}\right)$; Carbon Monoxide $(\mathrm{CO})$; and Carbon Dioxide $\left(\mathrm{CO}_{2}\right)$. Note that while both the GRIMM 11-D and Teledyne T640 also report $\mathrm{PM}_{10}$, that parameter was not used for LCS mobile evaluation due to nonideal sampling duct aspiration efficiency for PM I $_{10}$ (Figure S1).

'Note that while some reference analyzers used have a US EPA Federal Reference/Equivalent Method (FRM/FEM) designation, their use in a GBMP should not be construed as meeting FRM/FEM requirements, mainly owing to operation in a nonstationary application and using different averaging timescales. See Section 11 in this Supporting Information for more details.

¥The particle diameter ranges for these instruments are as follows:

- $\quad$ GRIMM 11-D: 0.253 to $35.15 \mu \mathrm{m}$

- Teledyne T640: 0.18 to $20 \mu \mathrm{m}$

- $\quad$ ADI MAGIC CPC: 0.005 to $2.5 \mu \mathrm{m}$

- DMT PAX: N/A (no size selection or range listed) 


\section{Transverse Duct Sampling System}

Google safety requirements precluded a sampling system that could either 1) injure pedestrians/cyclists or cause property damage if struck by exterior fixtures, or 2) enter the frame of view of the Google Street View camera, which had a $360^{\circ}$ viewing angle. This ruled out the use of masts, probes mounted on the rooftop, or probes that extend from the sides the vehicle beyond the sideview mirrors.

The main section of the transverse sampling duct was made of a 48-inch $(1.22 \mathrm{~m})$ long segment of galvanized steel duct with a square cross-section measuring 8 inches $(0.2 \mathrm{~m})$ per side. The main section had a volume of $1.77 \mathrm{ft}^{3}\left(0.05 \mathrm{~m}^{3}\right)$. The sample air inlet and egress of the duct was equipped with 11-inch $(0.28 \mathrm{~m})$ long adapters that transitioned to 4-inch $(0.1 \mathrm{~m})$ round segments. Both duct ends were then terminated with Versa 3050 Type B Gas Vent round weather caps, which had four 7-inch $(0.18 \mathrm{~m})$ diameter louvers that prevented rain from entering, as well as reducing exterior turbulent eddies in the sample stream. Since no GBMP component could interfere with the GSV camera view, the sampling duct was located at 54 inches $(1.4 \mathrm{~m})$ above ground.

The flow in the sampling duct was provided by an inline axial fan installed near the exterior portside of the sampling duct, so that ambient air was drawn into the duct from the starboard side of the GBMP. The fan voltage was controlled based on the measured duct flow velocity to maintain non-turbulent flow conditions $(0.15 \mathrm{~m} / \mathrm{s}$ flow velocity, approximately $371 \mathrm{lpm}$ flow rate, and approximately 8.1 second residence time). The total sampling flow rate for the reference particle analyzers was $7.5 \mathrm{lpm}$ and the isokinetic PM probe in the duct had an inlet diameter of $0.0326 \mathrm{~m}$ to match the duct flow velocity.

Different options for aerosol conditioning were considered, and ultimately diffusion drying via silica gel was identified as the optimal solution for aerosol drying on the GBMP: a) Dilution with dry air requires a source of air, either from a cylinder or by pumping air through a diffusion dryer; the former solution presenting safety concerns regarding transport of pressurized cylinders and the latter requiring additional power draw for the pump. In addition, increased particle losses can occur when trying to mix two airflows together. b) Heating the sample can also remove particle-bound moisture, but risks volatilizing organic components of particles, imposes a power demand, and comes with the limitation that moisture can re-condense onto particles when the sample leaves the heated lines and enters an instrument. c) Diffusion drying via silica gel increases residence times and diffusional losses of ultrafine particles. It is also labor intensive in that the silica gel needs to be replaced and regenerated, but at least the power requirements are outsourced to an offline oven. d) Diffusion drying via water-permeable polymer (i.e. Nafion) can result in fewer losses of ultrafine particles compared to using silica gel (because the Nafion tubing is small in diameter and so the residence time is smaller). However, this solution requires an externally-provided counterflow of dry air, which means a dry air cylinder, or a pump and another diffusion dryer.

The Aerocalc [1] and the Particle Loss Calculator [2] tools were used to estimate particle losses from the sampling system. Figure S1 shows modeled particle efficiencies by GBMP velocity, accounting for diffusional, gravitational, and inertial losses through the sampling duct and PM probe combined, using the Particle Loss Calculator tool. Particles with diameters less than $2.5 \mu \mathrm{m}$ are expected to be efficiently sampled at all GBMP velocities (at worst, $70 \%$ efficiency at 65 
miles per hour); in contrast, particles with diameters of $10 \mu \mathrm{m}$ are estimated to not be sampled at over 10\% efficiency when the GBMP velocity exceeds 5 miles per hour. Further efforts are needed to improve the sampling system for $\mathrm{PM}_{10}$, so it is not currently an evaluated pollutant. The Particle Loss Calculator tool returned values based on inputs within the range of applicability for the equations used to calculate efficiency for only a portion of the stationary scenario curve; estimates for other velocities are likely overestimating efficiency. Note that particle losses were not estimated for sampling lines downstream of the PM probe; instead particle losses were experimentally measured for each PM instrument by comparing steady-state ambient concentrations with the instrument connected and disconnected from the sampling system. The data treatment process accounts for these experimentally determined particle losses.

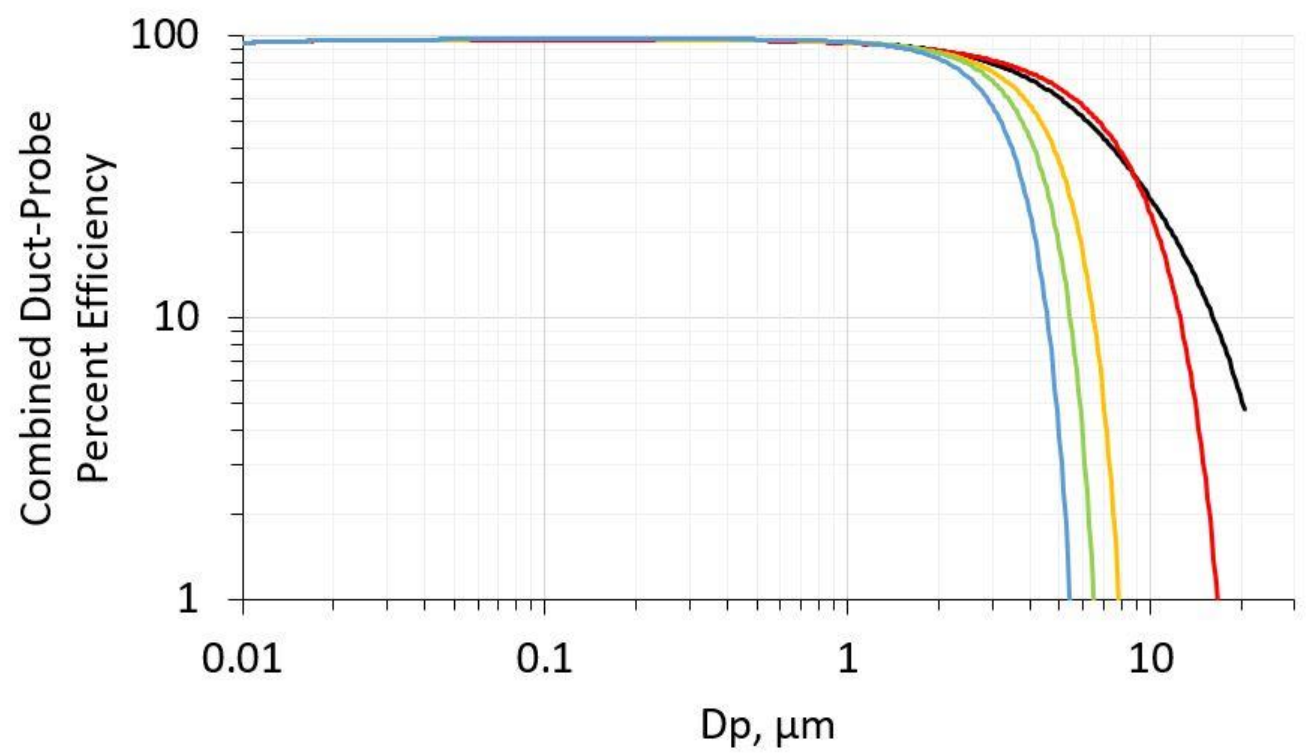

$$
-0 \mathrm{mph}-5 \mathrm{mph}-30 \mathrm{mph}-45 \mathrm{mph}-65 \mathrm{mph}
$$

Figure S1: Estimated particle total efficiency (product of aspiration and penetration efficiencies) for particles through the combined sampling duct and PM probe by GBMP velocity (units are miles per hour). Estimates made with the Particle Loss Calculator tool [2].

To minimize losses of gas species in samples obtained, short lengths of nonreactive sampling line material was used (i.e. PTFE tubing, ozone-conditioned stainless-steel manifold). 


\section{Test Route}

A variety of test routes throughout the South Coast AQMD jurisdictional area were piloted in the summer of 2019. Observed pollutant ranges for the pilot routes are listed in Table S2.

Table S2: Piloted GBMP evaluation test routes.

\begin{tabular}{|c|c|c|c|c|c|}
\hline $\begin{array}{l}\text { Route } \\
\text { Name }\end{array}$ & Route Geographic Focus & $\begin{array}{l}\text { PM2.5 } \\
\text { Range }^{*} \\
\left(\mu \mathrm{g} / \mathrm{m}^{3}\right)\end{array}$ & $\begin{array}{l}\text { PM10 } \\
\text { Range* } \\
\left(\mu g / m^{3}\right)\end{array}$ & $\begin{array}{l}\mathrm{O}_{3} \\
\text { Range* } \\
\text { (ppbv) }\end{array}$ & $\begin{array}{l}\mathrm{NO}_{2} \\
\text { Range* } \\
\text { (ppbv) }\end{array}$ \\
\hline DTLA & Downtown Los Angeles & $5-15$ & $8-25$ & $2-60$ & $10-70$ \\
\hline LA-SFV & $\begin{array}{l}\text { Central Los Angeles and San Fernando } \\
\text { Valley }\end{array}$ & $5-30$ & $5-50$ & $1-70$ & $10-60$ \\
\hline $\mathbf{L B}$ & Long Beach & $5-15$ & $5-30$ & $1-60$ & $5-60$ \\
\hline PCH & $\begin{array}{l}\text { Pacific Coast Highway and Orange } \\
\text { County }\end{array}$ & $3-15$ & $5-25$ & $15-50$ & $3-40$ \\
\hline IE-SGV & Inland Empire and San Gabriel Valley & $3-30$ & $5-50$ & $1-70$ & $5-60$ \\
\hline $\begin{array}{l}\text { RC-PS- } \\
\text { Crest }\end{array}$ & $\begin{array}{l}\text { Riverside County, Palm Springs, and } \\
\text { Crestline }\end{array}$ & $3-20$ & $5-40$ & $1-100$ & $1-80$ \\
\hline
\end{tabular}

*Expected approximate concentration ranges based on drives conducted by the AQ-SPEC mobile platform in summer 2019; tests conducted in a different season or year may report significantly different pollutant concentrations.

The route driving through the Inland Empire and San Gabriel Valley (IE-SGV) was ultimately determined to provide the optimal testing conditions. The test route is shown in Figure S2.

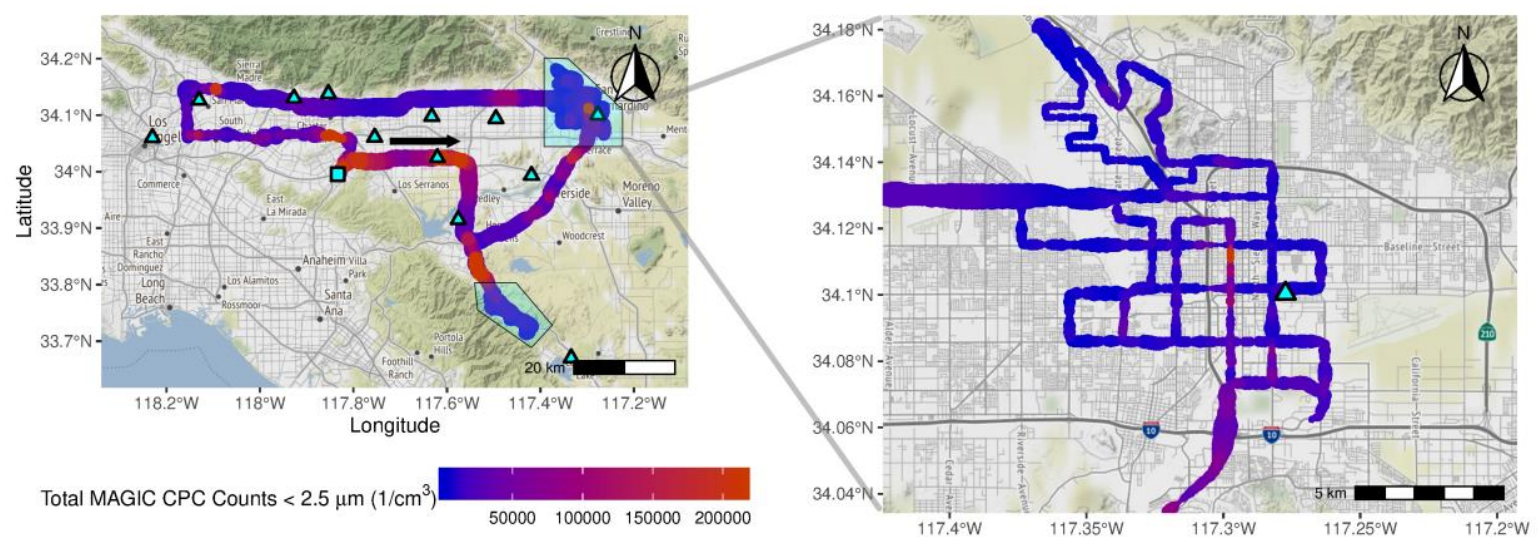

Figure S2: The LCS evaluation route started at South Coast AQMD headquarters (cyan square), heading eastward in a loop through the Inland Empire and San Gabriel Valley on highways. Due to ubiquitous congestion in the region, a wide variety of vehicle speeds were still attained on highways. The route also included arterial and local roads when driving through the San Bernardino and Temescal Valley communities (northern and southern cyan shaded areas, respectively) in Southern California. Regulatory air monitoring stations near the route that measure at least one criteria pollutant are shown as cyan triangles. The MAGIC CPC data shown is an example of high time resolution reference analyzer data collected on a single test drive. The points are colored by total particle counts, with values outside the 1-99 percentile range coerced to narrower color scale limits so that most values can be distinguished on a color gradient (lowest and highest color scale-coerced values from the map were 2,148 and $>1 \times 10^{6} \mathrm{~cm}^{-3}$, respectively). Higher value points are plotted above lower value points. Points are sized to qualitatively indicate GBMP speed.

Routes were designed by AQ-SPEC staff in Google My Maps. Breaks and meal stops for the driver were included in the routes. Driver break points were in areas with various food options, restroom availability, and parking options that were secure, had high public visibility, and had direct lineof-sight between the driver and the GBMP. If the driver noticed unusual instrument activity, during 
these breaks when the GBMP was not moving, the driver recorded notes and called AQ-SPEC staff for guidance.

The GBMP driver navigated the test routes using the OsmAnd app (https://osmand.net), a mobile phone app that allows for uploading a KML/KMZ route file for offline, fixed, navigation for a driver (as opposed to Google Maps or Waze that dynamically change navigation directions based on traffic) that was employed by AQ-SPEC staff for the purposes of this work 


\section{Safety Considerations}

While all possible efforts were taken to minimize hazards, this evaluation protocol posed inherent risks to personnel constructing and operating a GBMP, as well as other drivers, cyclists, pedestrians, and property, due to the high-speed operation of a motor vehicle outfitted with substantial electrical equipment. Care was taken that GBMP components did not 1) obstruct driver lines of sight, 2) prevent emergency egress, and 3) detach or strike objects or people. Electrical precautions were taken during installation, operation, and battery recharging. No hazardous chemicals or gas cylinders were transported. The driver was solely focused on navigation, and did not troubleshoot instruments or view data while the GBMP was in motion. No passenger was present. 


\section{LCS Installation Details by Scenario}

\subsection{Scenario 1}

In Scenario 1, LCS were evaluated by mounting 1) in the galvanized steel sampling duct if the LCS sample intake was driven by a fan or 2) on the instrumentation rack and sampling from the reference gas analyzer manifold or reference particle analyzer manifold if the LCS sample intake was driven by a pump and easily connected to gas fittings. Fan-based LCS could be mounted radially around the duct flow centerline if they were small enough, and if larger, serially along the sampling duct such that the LCS inlet was perpendicular to the duct flow centerline. The flow around the LCS was controlled to be non-turbulent. The inside of the GBMP was maintained at $21-24^{\circ} \mathrm{C}$ using the vehicle air conditioner controller and the air conditioning system was continuously on recirculation mode (but not necessarily the same condition applies to the inside of the sampling duct). Sensor units were tested in triplicate.

An installation diagram for Scenario 1 is shown in Figure S3.

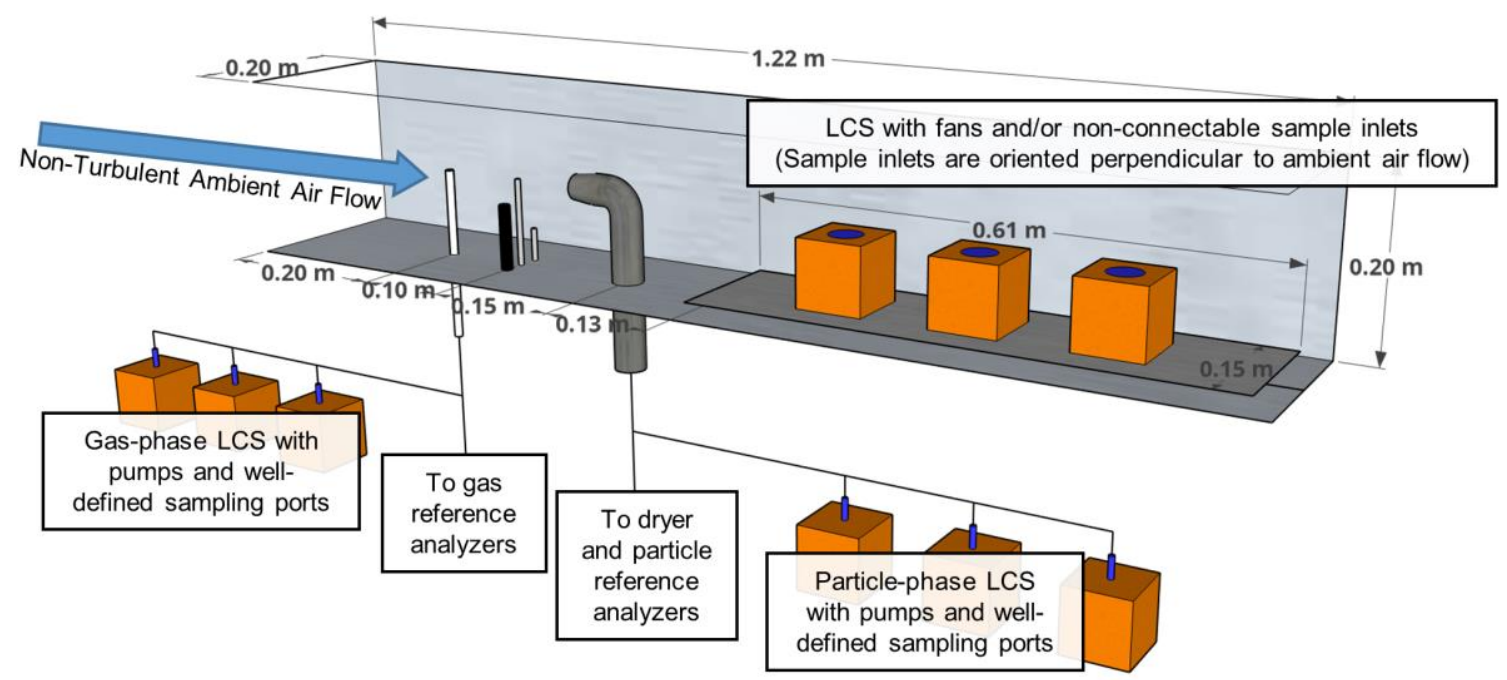

Figure S3: Triplicate LCS installation diagram for Scenario 1 testing in the transverse sampling duct of the 2009 Hyundai Santa Fe GSV GBMP. Ambient air flow velocity through the duct was controlled to non-turbulent velocities with a fan on the exhaust end of the duct. LCS sample inlets are represented in dark blue. If the LCS had pumps and well-defined sampling ports, they sampled from one of the common reference analyzer probes and were mounted in the vehicle cabin. Otherwise, LCS were mounted to the sliding test tray behind the reference particle analyzer probe with sample inlets oriented perpendicular to the ambient air flow direction and were wholly enveloped in the ambient air flow.

\subsection{Scenario 2}

In Scenario 2, LCS were exposed to partially uncontrolled flow conditions by placement inside of a polyethylene enclosure box (interior dimensions of $16.25 \times 8.63 \times 6.75$ inches or $0.4 \times 0.2 \times 0.2$ m) secured to the GBMP rooftop rack. Three holes were cut into the box: one each in the front, top, and back faces (respective to the direction of GBMP travel). A blast gate was installed over each hole so that certain holes could be opened or closed to allow for two different air flow paths to be tested: a front-to-back flow path (FTB / Scenario 2A; front and back holes opened, top hole closed) and a top-to-back flow path (TTB / Scenario 2B; top and back holes opened, front hole closed). The temperature inside the box was not maintained. LCS were mounted such that their inlets were perpendicular to the flow path (typically this meant the LCS inlets were facing up). 
For each flow path, a preliminary testing scenario was conducted in which LCS were spaced equidistantly across the width of the box, and LCS units were rotated among the positions across test drives until each unit had collected data in each of the positions at least once. An optimal location in the box was identified for that LCS based on the LCS-reference $\mathrm{R}^{2}$, and this location determined where LCS were clustered for Scenario 2A and 2B testing (see Figure S13 for example preliminary Scenario 2 positioning data). Reference analyzers still sampled from the duct.

An installation diagram for both the preliminary part of Scenario 2, and Scenario 2 after the optimal LCS location within the box has been identified, is shown in Figure S4.

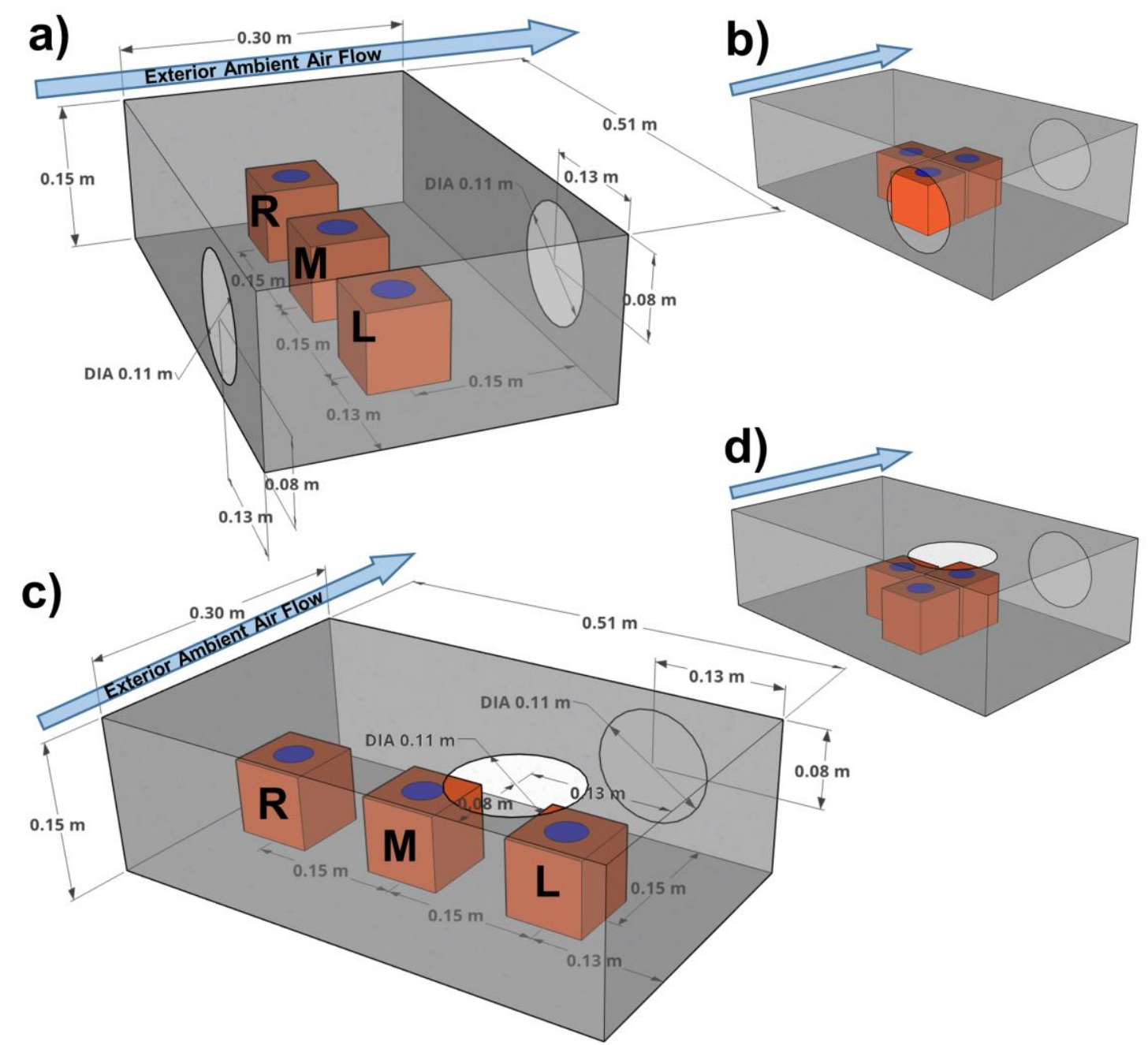

Figure S4: Triplicate LCS installation diagram for Scenario 2 testing in the rooftop enclosure box. The exterior ambient air velocity was primarily dependent on the vehicle velocity. Ambient air flow around an LCS was only partially moderated by the enclosure box, depending on the LCS position within the box. LCS sample inlets are represented in dark blue. These installations applied to an LCS model regardless of the use of a fan/pump for sample aspiration or the presence of a well-defined sampling inlet port. LCS sample inlets were oriented perpendicular to the flow path in the box. a) Preliminary Scenario 2 testing arrangement with a front-to-back (FTB) flow path through the enclosure box. Each LCS within a triplicate was tested in each position at least once. "L", "M", and "R" indicate the left, middle, and right installation positions in the box, respectively, when facing the direction of travel. b) Scenario 2A FTB testing arrangement, in which LCS were installed in a tight cluster in the optimal location identified in Preliminary Scenario 2 FTB testing. The example illustration pertains to the case that placing the LCS in the center of the box, offsetting them from the flow path, resulted in the optimal performance compared to the reference analyzers. c) Preliminary Scenario 2 testing arrangement with a top-to-back (TTB) flow path through the enclosure box. Each LCS within a triplicate was tested in each position at least once. "L", "M", and " $\mathrm{R}$ " indicate the left, middle, and right installation positions in the box, respectively, when facing the direction of travel. d) Scenario 2B TTB testing arrangement, in which LCS were installed in a tight cluster in the optimal location identified in Preliminary Scenario 2 TTB testing. The example illustration pertains to the case that placing the LCS in the center of the box, offsetting them from the flow path, resulted in the optimal performance compared to the reference analyzers. 


\subsection{Scenario 3}

In Scenario 3, LCS were exposed to completely uncontrolled conditions by mounting directly to the rooftop rack above the GBMP windshield, and LCS were not housed or covered. Three sample inlet orientations were tested in this scenario: 1) in the mounting configuration such that the sample inlet orientation matches that instructed, recommended, or suggested by user manuals, brochures, or vendor images of the unit ("default" / Scenario 3A); 2) such that the sample inlet orientation faced the GBMP direction of travel (facing-forward / "FF" / Scenario 3B), and 3) such that the sample inlet orientation faced away from the GBMP direction of travel (facing backward / "FB" / Scenario 3C). Reference analyzers still sampled from the sampling duct.

An installation diagram for Scenario 3 is shown in Figure S5.

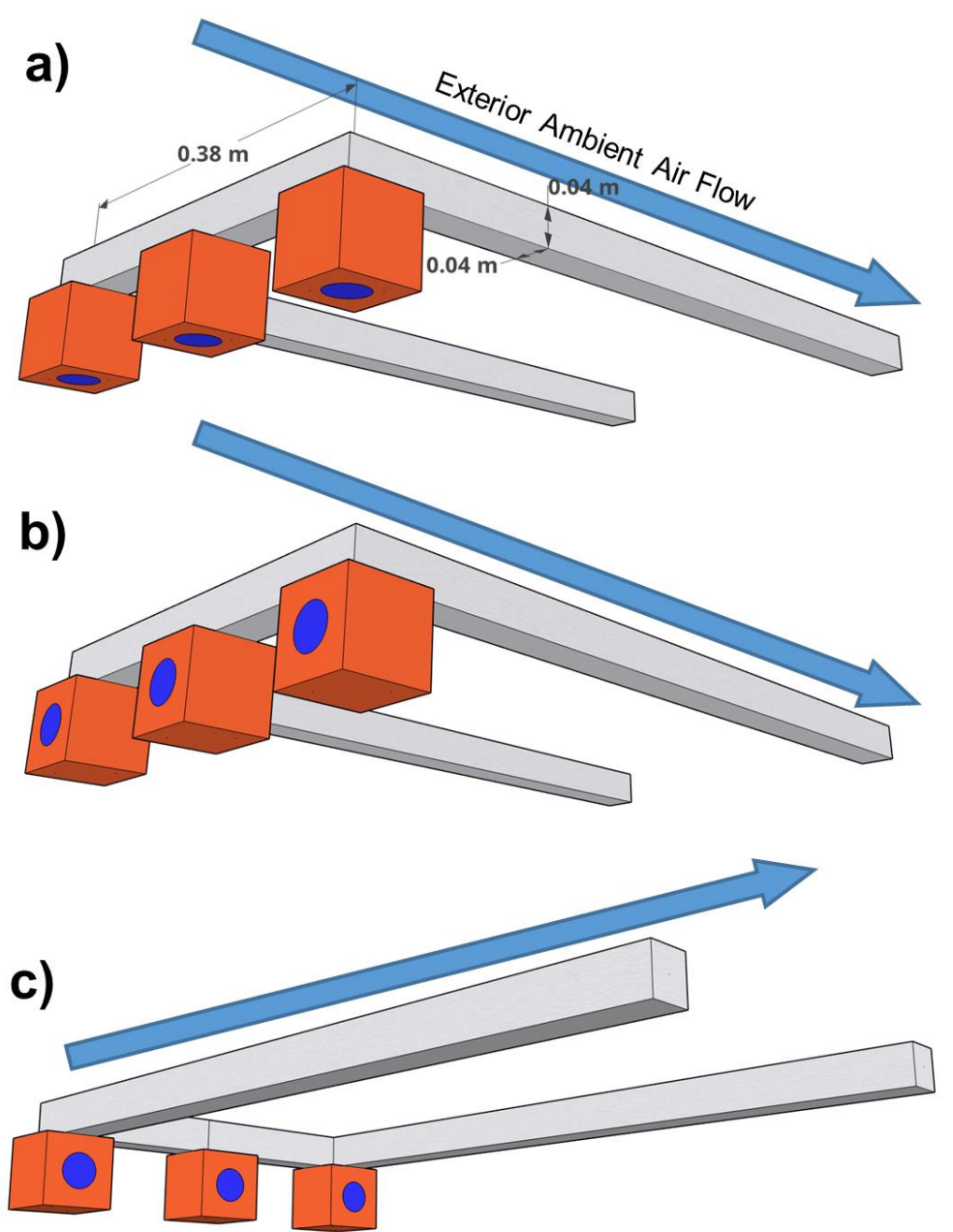

Figure S5: Triplicate LCS installation diagram for Scenario 3 testing on the rooftop frame. The rooftop frame was positioned at a height of 0.20 meters above the vehicle roof. The exterior ambient air velocity was primarily dependent on the vehicle velocity. Ambient air flow around an LCS was completely uncontrolled. LCS sample inlets are represented in dark blue. These installations applied to an LCS model regardless of the use of a fan/pump for sample aspiration or the presence of a well-defined sampling inlet port. a) Scenario 3A "default" testing arrangement, in which LCS were installed with the sample inlet in the orientation that is recommended in vendor manuals or seen in marketing material. The illustration shows an example case in which the LCS sample inlet is intended to face the ground. In the case that an LCS "default" orientation is facing forward or backward, then the Scenario 3A testing arrangement installed the LCS such that the sample inlet orientation was perpendicular to the direction of travel. b) Scenario 3B "facing forward" (FF) testing arrangement, in which LCS were installed with the sample inlet facing the direction of travel. c) Scenario 3C "facing backward" (FB) testing arrangement, in which LCS were installed with the sample inlet facing away from the direction of travel. 


\section{Co-locations}

The GBMP was co-located while stationary with the South Coast AQMD Riverside-Rubidoux, Lake Elsinore, Long Beach Route 710 Near Road, or Long Beach Hudson Air Monitoring Stations (AMS) in Southern California at least once per test scenario for at least 2 hours. This co-location served as a check that the reference analyzers reported values consistent with those from an AMS stationary reference analyzers. The GBMP sampled as close to the AMS instrument inlets as practicably allowable (within 3-10 m). During co-location the GBMP engine and air conditioning were off, and the GBMP power system was connected to an electrical outlet if it was available on the premises. Sunshades covered the windows and the trunk was opened to minimize heat gain. Co-locations for $\mathrm{O}_{3}$ and $\mathrm{PM}_{2.5}$ reference analyzers are shown in Figure S6. Note that the GRIMM 11-D does not hold US EPA FEM designation for $\mathrm{PM}_{2.5}$ and showed large disagreements with the T640 and regulatory AMS PM 2.5 monitors, which possess US EPA FEM designation. It is also important to note that while the T640 and T400 FEM designations apply during stationary colocations, their non-stationary use in a GBMP during test drives should not be construed as meeting FEM requirements; nonetheless, the use of reference instruments with FEM designations was selected to maximize confidence in output readings.
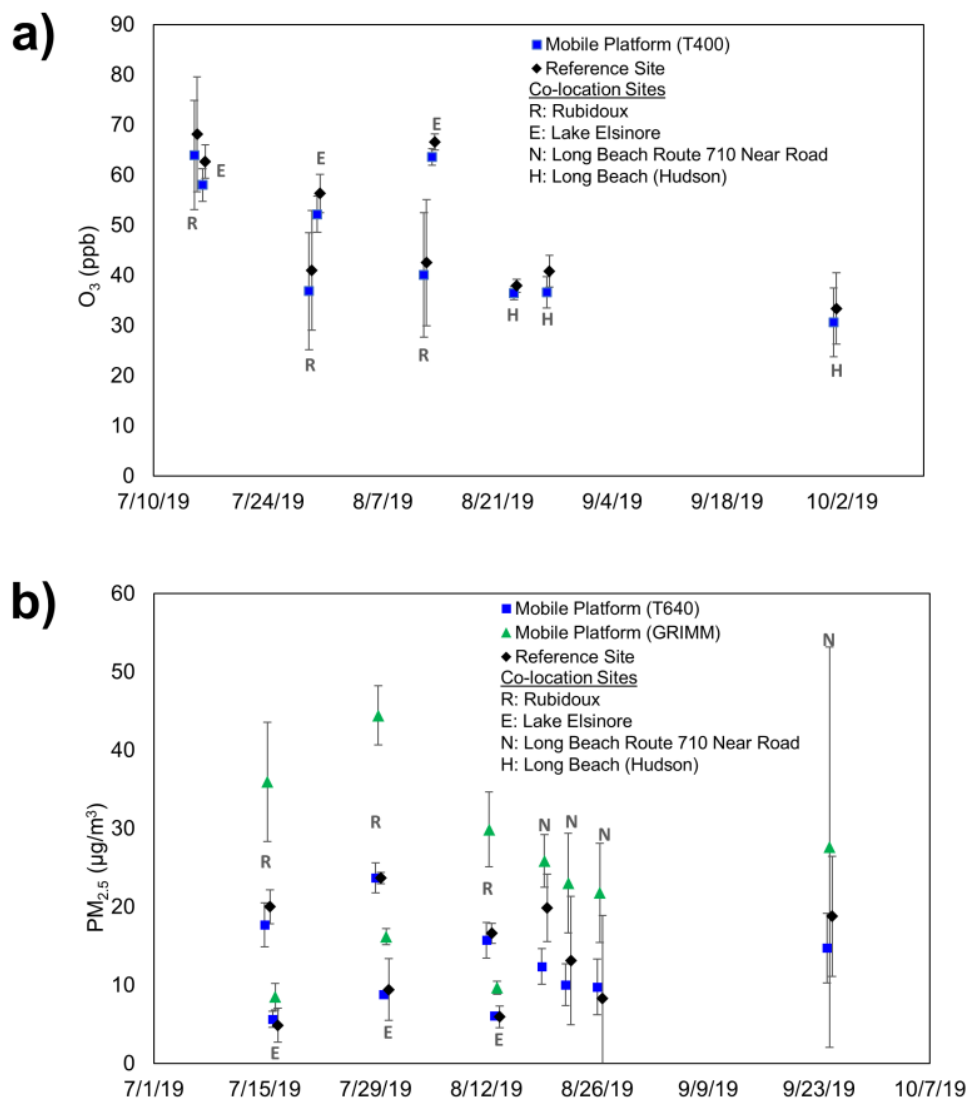

Figure S6: GBMP and regulatory AMS co-locations for a) $\mathrm{O}_{3}$ and b) $\mathrm{PM}_{2.5}$ during the evaluations of the example gas and PM LCS. The GBMP $\mathrm{O}_{3}$ reference analyzer was within \pm 1 SD of the AMS during co-locations. The GBMP T640 $\mathrm{PM}_{2.5}$ reference analyzer was within \pm 1 SD of the AMS during colocations except for 8/19/2019 event; subsequent corrective actions brought the GBMP T640 back into agreement with AMS values. The GBMP GRIMM 11-D reference analyzer usually overestimated $\mathrm{PM}_{2.5}$ and was often not within $\pm 1 \mathrm{SD}$ of the AMS; LCS were not judged against the GRIMM 11-D during this evaluation, except for determining optimal location within a rooftop enclosure for Scenario 2 testing. Note that the GRIMM 11-D does not have US EPA FEM PM ${ }_{2.5}$ designation like the T640 and the $\mathrm{PM}_{2.5}$ instruments at regulatory AMS stations. 


\section{Testing Details}

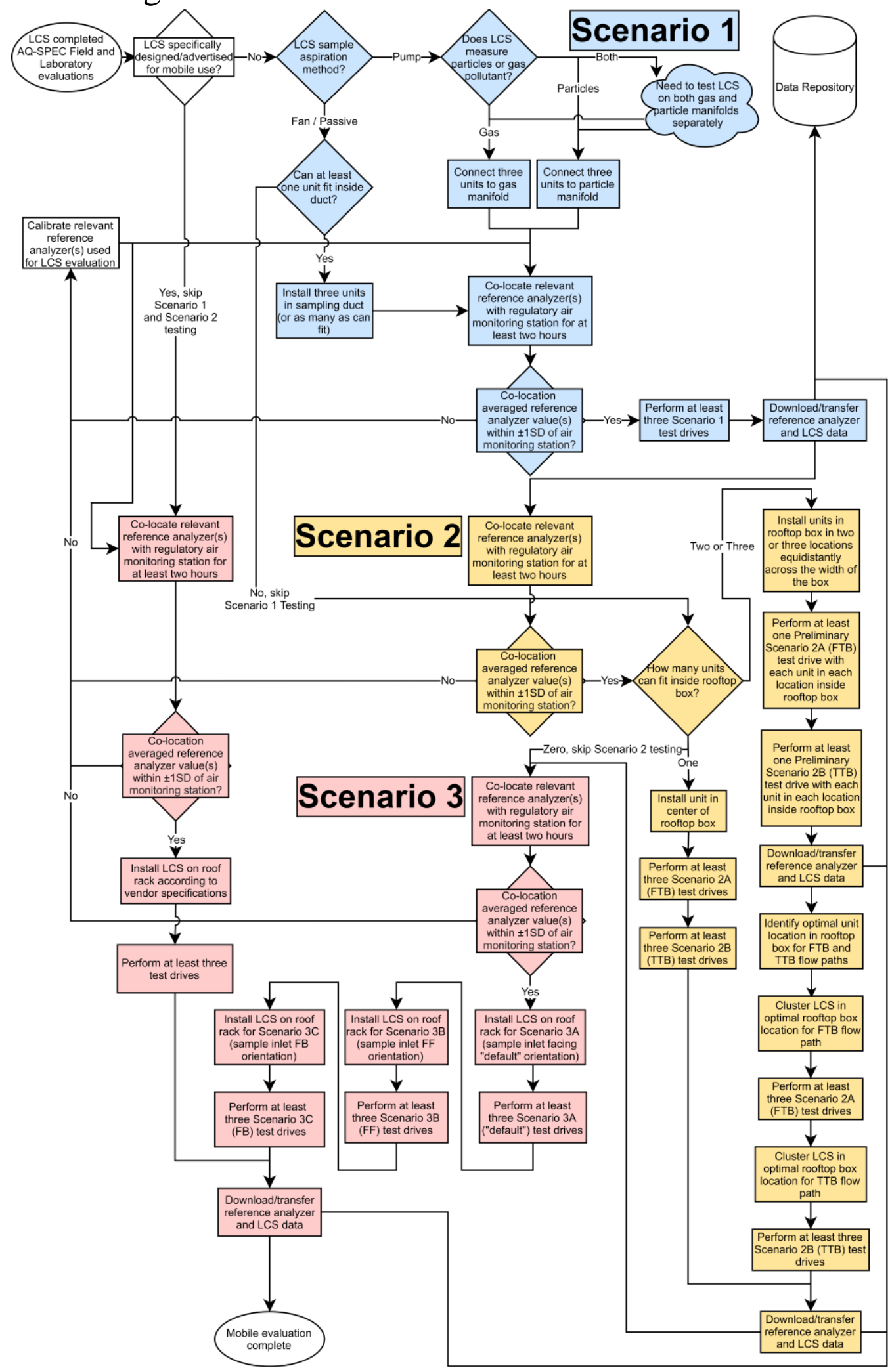

Figure S7: Detailed process flow diagram for testing aspects of the AQ-SPEC LCS mobile evaluation protocol. 


\section{Data Treatment Details}

The data treatment process flow diagram is shown in Figure S8.

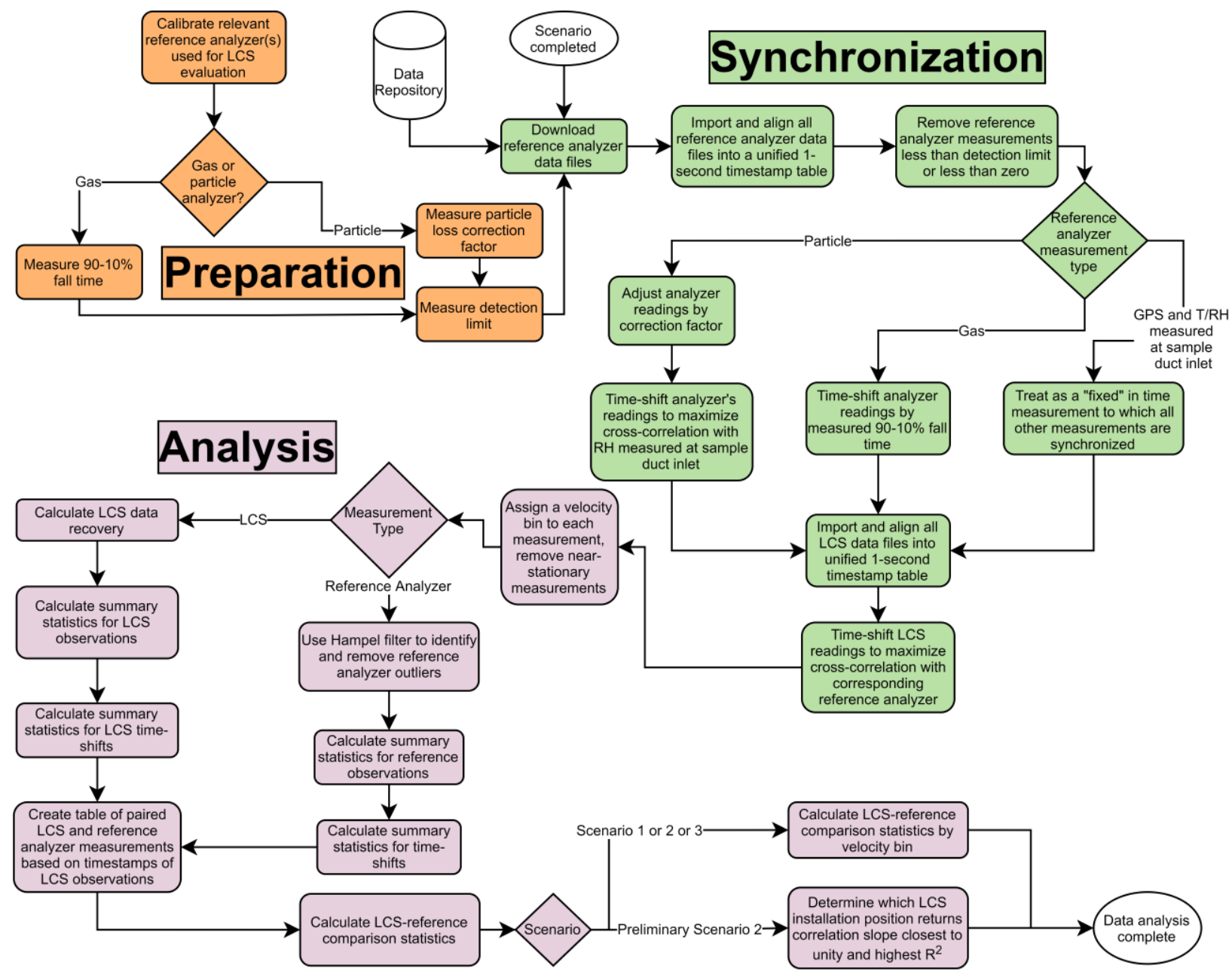

Figure S8: Detailed process flow diagram for data analysis aspects of the AQ-SPEC LCS mobile evaluation protocol.

Particle reference analyzer concentrations were corrected to account for losses in the sampling duct and lines. While the GBMP was stationary with windows fully open, particle analyzers sampled steady-state ambient concentrations while connected to the PM manifold (sampling from the duct) and then disconnected from the PM manifold (sampling without any duct or line losses). Three of these measurements were conducted and then averaged to obtain a loss correction factor (the ratio of the concentration while sampling without any losses to the concentration while sampling from the manifold).

Two methods were used to synchronize measurements from the reference and LCS data in the GBMP: 1) signal "fall time" measurement and 2) time delay cross-correlation.

For gas reference analyzers, the delay time was determined with signal fall time measurements (the time it takes for a steady-state concentration to fall from $90 \%$ to $10 \%$ ). A three-way valve connected the common gas analyzer probe to the ambient air and a zero-air gas cylinder. Initially 
reference analyzers sampled ambient air until a steady concentration was achieved, and then the valve was switched so that reference analyzers sampled zero-air. Measurements were repeated three times, and the instrument delay time was the mean of the fall time measurements.

Since it was not possible to supply a step change of filtered air or a steady particle concentration into the entire duct, PM analyzer delay times were determined using time delay cross-correlation [3]. The reference $R H$ meter in the sampling duct (Fisherbrand Traceable Humidity Meter) was chosen as the temporally-fixed signal against which all other reference equipment ambient $R H$ signals were synchronized against, since the reference $R H$ measurement was collected nearest to the duct inlet. Equipment that did not measure ambient $R H$ but shared another common parameter with equipment that had been synchronized to the reference $R H$ measurement, were subsequently synchronized using the common parameter (for example PM values from the T640 and the GRIMM 11-D). This procedure was conducted in $R$ using the $c c f$ function in the stats package [4, $5]$.

LCS data were also synchronized to reference analyzer data by using the time delay crosscorrelation technique to align LCS concentrations to the concentrations from a reference analyzer measuring the same pollutant as the LCS. The time shifts applied to the LCS were averaged across the triplicate set of units for a given installation scenario; this can be reported to the consumer as the average lag time for that LCS model, for both a specific installation scenario and across all installation scenarios.

Reference analyzer data was screened to remove erroneous readings and outliers. Erroneous readings included physically unrealistic measurements (negative or zero concentrations of a pollutant; an exception to this being the case that negative values should be retained for averaging purposes to obtain the true value, but only if recommended by the instrument manufacturer or warranted by the measurement principle), measurements below the instrument's detection limit, or PM readings when the sample $R H$ measured by the analyzer (which would have been downstream of the silica gel dryer) exceeded $50 \%$, in which case the reference analyzer could potentially overestimate PM. In addition, while $T / R H$ was not measured in the vehicle cabin, reference analyzer data included flags and measurement temperatures that were used to also identify low quality data for removal. Outliers were detected using a Hampel filter (hampel function in the pracma package of $R$ [6]) using a 5-minute moving window and a threshold corresponding to Pearson's 3-sigma rule. Reference data was also assigned to GBMP velocity bins of 1) bicycling speed ranges (3-15 miles per hour), 2) local road speed ranges (15-30 miles per hour), 3) arterial road speed ranges (30-50 miles per hour), and 4) highway speed ranges (60-80 miles per hour). Data collected at vehicle speeds $<3$ miles per hour were omitted from analysis because of the potential for self-sampling of emissions; however we recognize that some community scientists may not be familiar with how to filter out data by vehicle velocity, so we may in the future develop assistive notes on approaches they can use.

The GBMP evaluation of the sensors was based on a side-by-side comparison between the LCS being tested and the reference instrument(s) measuring the same pollutant(s). The evaluation parameters included: 
- Means, quartiles, ranges

- Absolute and relative standard deviations (SD, RSD)

- Mean bias, mean absolute, and root mean square errors (MBE, MAE, RMSE)

- Mean and median absolute deviations (Mean AD, Median AD)

- Precision

- Range-based, absolute, and relative intra-model variabilities (IMV)

- Pearson's coefficient of determination $\left(\mathrm{R}^{2}\right)$

- Data recovery

- Optimal location inside an enclosure for Scenario 2 for each flow path (FTB and TTB)

- $\mathrm{R}^{2}$ by velocity for a given test scenario, flow path, and inlet orientation

The range-based intra-model variability (IMV) is a measure of dissimilarity across a triplicate set of LCS, quantified as:

$$
\operatorname{IMV}(\%)=\frac{\max \left(\overline{\mathrm{LCS}}_{1}, \overline{\mathrm{LCS}}_{2}, \overline{\mathrm{LCS}}_{3}\right)-\min \left(\overline{\mathrm{LCS}}_{1}, \overline{\mathrm{LCS}}_{2}, \overline{\mathrm{LCS}}_{3}\right)}{\frac{\sum\left(\overline{\mathrm{LCS}}_{1}, \overline{\mathrm{LCS}}_{2}, \overline{\mathrm{LCS}}_{3}\right)}{3}} \times 100 \%
$$

where $\overline{\mathrm{LCS}}_{\mathrm{j}}$ is the average concentration value for the $\mathrm{j}^{\text {th }}$ test sensor unit of the triplicate for each test drive.

The absolute IMV is the standard deviation of the means of the time-matched readings from the triplicate of sensors. The relative IMV is the absolute IMV divided by the grand mean of the time-matched readings from the triplicate of sensors.

Data recovery is the percentage of the number of sensor data points that are valid out of the total number of data points that should have been collected during the testing period (e.g. 4 hours of testing at 1-min time resolution results in up to 240 data points in total that should have been collected):

$$
\text { Data Recovery }(\%)=\frac{N_{\text {valid data }}}{N_{\text {test period }}} \times 100 \%
$$

where

$\mathrm{N}_{\text {valid data }}$ was the number of valid sensor data points during the testing period and

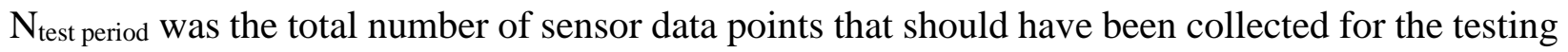
period (from start to end) if no data was lost or invalidated. 


\section{Example Gas LCS Additional Details}

\subsection{Particle Filters from Scenario 3}

Exceptionally high PM concentrations sampled by the POM LCS evaluated during Scenario 3 is illustrated by the clearly visible PM loading on the LCS inlet filters (Figure S9). In contrast, no visible PM loading was observed on filters that were replaced at the end of Scenarios 1 and 2.

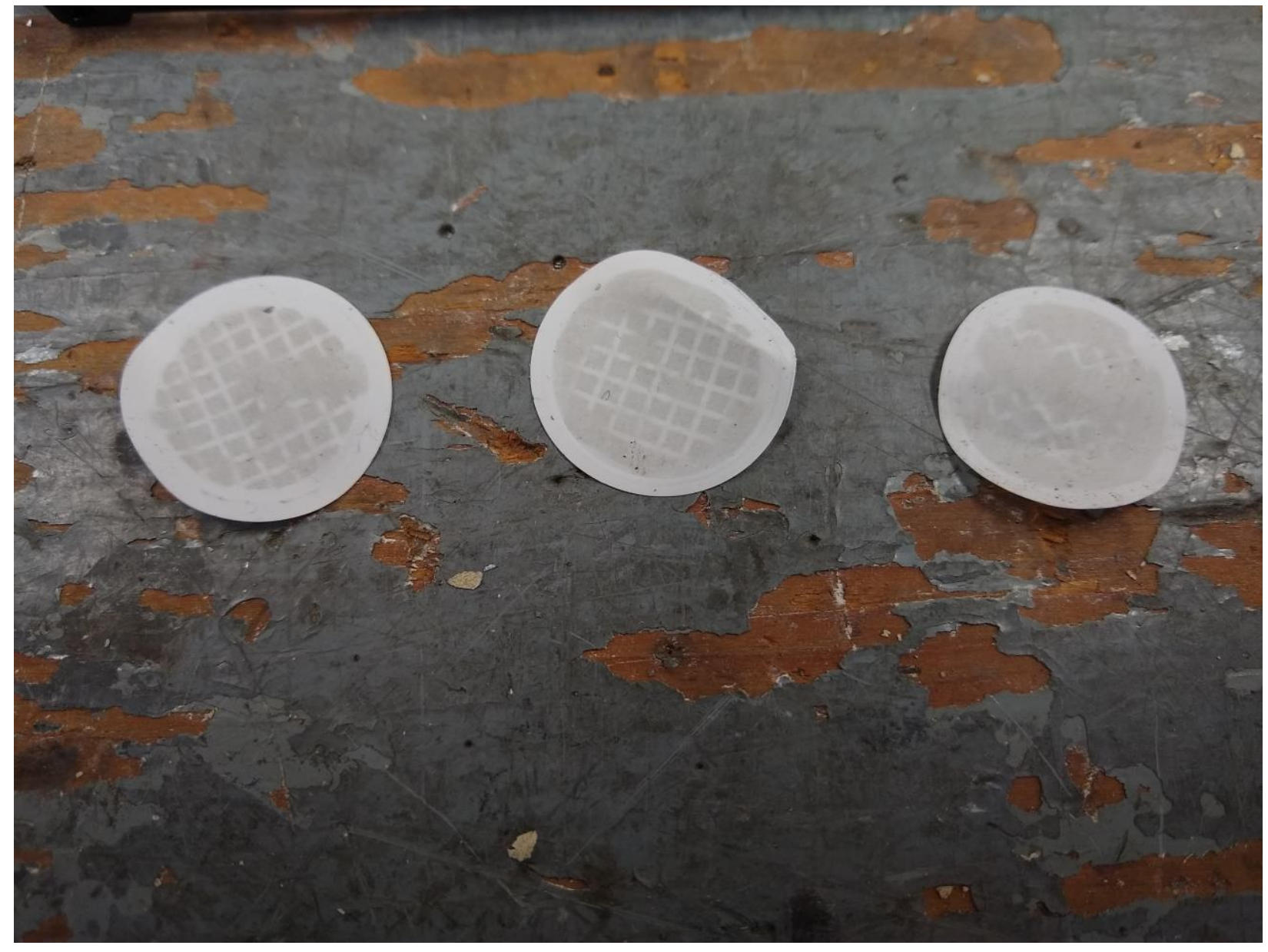

Figure S9: POM unit particle filters after conclusion of Scenario 3 testing. Particle loading was exceptionally visible, and may have been a contributing factor to noisy measurements from at least two units of the triplicate set. Increased replacement frequency of LCS consumables may need to be taken when exposing LCS in an uncontrolled environment during a mobile deployment.

\subsection{Individual Sensor Unit Evaluation Results}

The correlation plots of each POM unit compared to the reference analyzer, for every test scenario, is shown in Figure S10. Summary statistics of the reference analyzer and each POM unit, for every test scenario, are listed in Table S3. 
a) Scenario 1

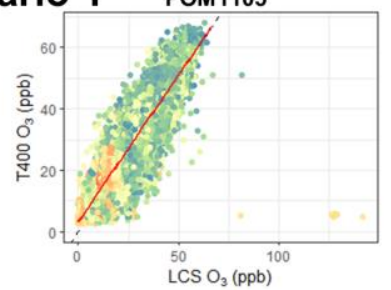

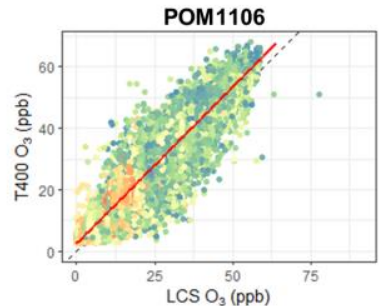

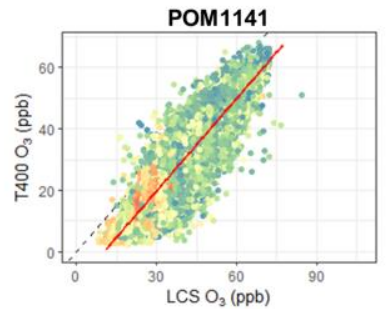

b) Scenario 2A (Front-To-Back Flow Path)
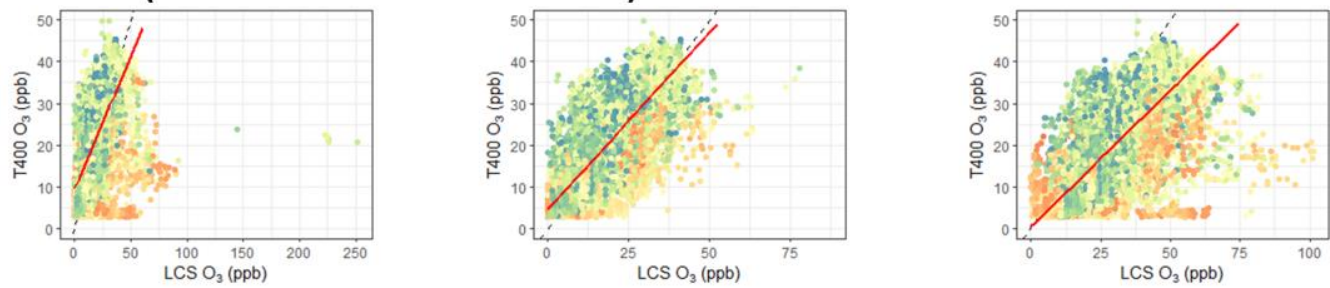

c) Scenario 2B (Top-To-Back Flow Path)
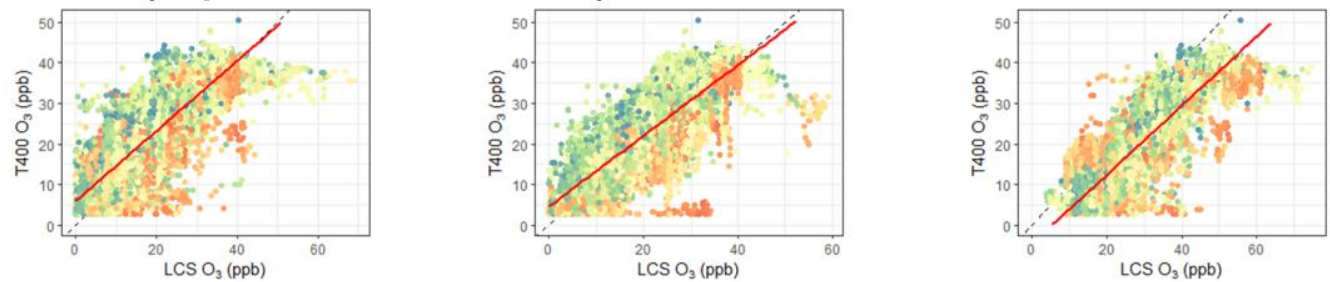

\section{d) Scenario 3A (Inlet Facing “Default” Direction)}
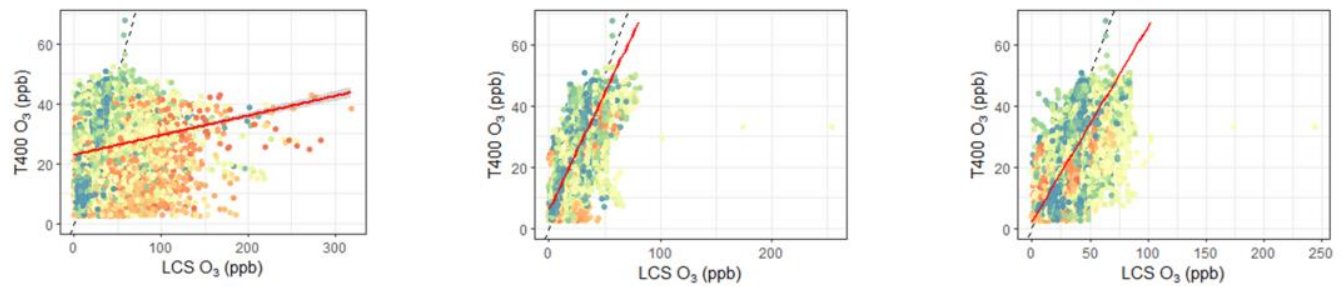

e) Scenario 3B (Inlet Facing Forward)
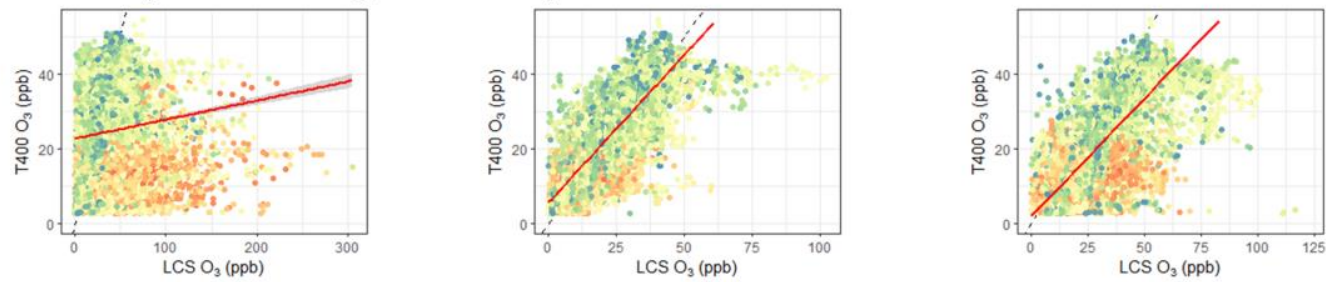

\section{f) Scenario 3B (Inlet Facing Backward)}
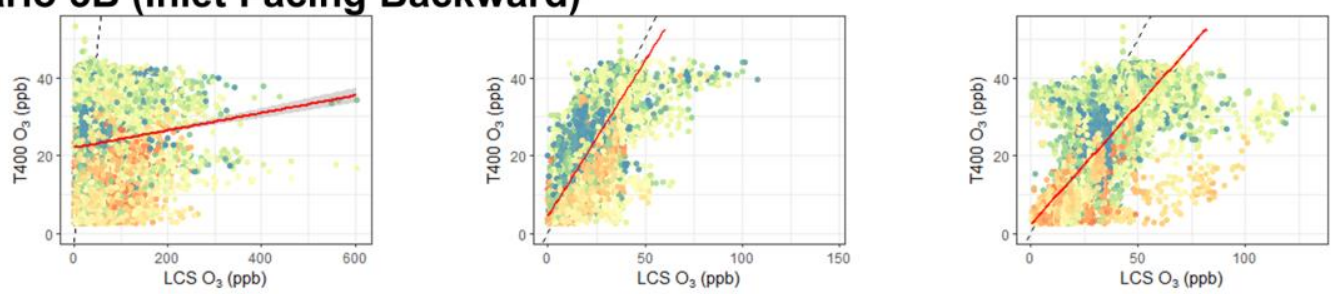

Figure S10: Correlation plots for the intra-unit $\mathrm{O}_{3}$ measurement values for the triplicate set of POM LCS units for each test scenario, with points colored by GBMP velocity. The dashed black line is the one-to-one line, the red line represents a linear regression mode, and the gray shaded area is the $95 \%$ confidence interval of the model (which may not be broad enough to be visible in all plots). 
Table S3: Summary statistics for the example gas $\left(\mathrm{O}_{3}\right)$ sensor (POM) evaluation in every test scenario, including those for the reference analyzer (T400), individual sensor units (intra-unit), and the sensor units as a group (intra-model)

\begin{tabular}{|c|c|c|c|c|c|c|c|c|c|c|c|c|c|c|c|c|c|c|c|c|c|c|c|c|c|}
\hline Unit & Scenario & $\begin{array}{l}\text { Min, } \\
\text { ppb }\end{array}$ & $\begin{array}{l}\text { Q1, } \\
\text { ppb }\end{array}$ & $\begin{array}{l}\text { Q2, } \\
\text { ppb }\end{array}$ & $\begin{array}{l}\text { Q3, } \\
\text { ppb }\end{array}$ & \begin{tabular}{|l|} 
Max, \\
ppb
\end{tabular} & \begin{tabular}{|l} 
Range, \\
ppb
\end{tabular} & \begin{tabular}{|l|} 
Mean, \\
ppb
\end{tabular} & $\begin{array}{l}\text { SD, } \\
\text { ppb }\end{array}$ & \begin{tabular}{|l|} 
RSD, \\
ppb
\end{tabular} & $\begin{array}{l}\text { Mean } \\
\text { AD, } \\
\text { ppb }\end{array}$ & \begin{tabular}{|l|} 
Median \\
AD, \\
ppb
\end{tabular} & \begin{tabular}{|l|} 
IMV \\
(Range), \\
$\%$
\end{tabular} & \begin{tabular}{|l|} 
IMV \\
(Absolute), \\
ppb
\end{tabular} & \begin{tabular}{|l|} 
IMV \\
(Relative), \\
$\%$
\end{tabular} & \begin{tabular}{|l|} 
MBE, \\
ppb
\end{tabular} & $\begin{array}{l}\text { MAE, } \\
\text { ppb }\end{array}$ & MBE/ & $\begin{array}{l}\text { RMSE, } \\
\text { ppb }\end{array}$ & $\begin{array}{l}\text { Residuals } \\
\text { SD, } \\
\text { ppb }\end{array}$ & Slope & $\begin{array}{l}\text { Slope } \\
\text { SE }\end{array}$ & Intercept & \begin{tabular}{|l|} 
Intercept \\
SE
\end{tabular} & $\mathbf{R}^{2}$ \\
\hline T400 & 1 & 2.7 & 20.8 & 30.7 & 37.6 & 69.9 & 67.2 & 29.3 & 12.4 & 42.4 & 10.0 & 8.1 & & & & & & & & & & & & & \\
\hline \begin{tabular}{|l|} 
POM1105 \\
\end{tabular} & 1 & 0.0 & 18.7 & 28.1 & 34.3 & 162.9 & 162.9 & 26.6 & 12.2 & 46.0 & 9.6 & 7.4 & & & & -2.2 & 4.2 & -0.5 & 5.6 & 5.2 & 0.96 & 0.00 & 3.30 & 0.06 & 0.82 \\
\hline POM1106 & 1 & 0.0 & 18.1 & 27.2 & 33.4 & 154.7 & 154.7 & 25.6 & 11.9 & 46.3 & 9.4 & 7.2 & & & & -2.9 & 4.4 & -0.7 & 5.6 & 4.7 & 1.02 & 0.00 & 2.51 & 0.06 & 0.85 \\
\hline \begin{tabular}{|l|} 
POM1141 \\
\end{tabular} & 1 & 6.3 & 30.6 & 40.3 & 46.3 & 167.6 & 161.3 & 38.3 & 12.4 & 32.2 & 9.8 & 7.4 & & & & 10.1 & 10.3 & 1.0 & 11.2 & 4.7 & 1.00 & 0.00 & -10.26 & 0.08 & 0.85 \\
\hline \begin{tabular}{|l|} 
Intra-model POM \\
\end{tabular} & 1 & 0.0 & 19.9 & 29.8 & 37.7 & 141.9 & 141.9 & 28.9 & 13.2 & 45.5 & 10.5 & 8.9 & 44.9 & 7.3 & 25.3 & 1.7 & 3.7 & 0.5 & 4.9 & 4.6 & 1.02 & 0.00 & -2.14 & 0.07 & 0.85 \\
\hline T400 & $2 \mathrm{~A}$ & 2.7 & 14.2 & 22.8 & 31.9 & 49.7 & 47.0 & 22.7 & 10.6 & 46.5 & 9.1 & 8.9 & & & & & & & & & & & & & \\
\hline POM1105 & $2 \mathrm{~A}$ & 0.0 & 10.6 & 18.8 & 25.8 & 251.9 & 251.9 & 19.0 & 11.1 & 58.7 & 8.7 & 7.7 & & & & -2.5 & 5.9 & -0.4 & 9.0 & 8.6 & 0.63 & 0.00 & 9.64 & 0.09 & 0.50 \\
\hline \begin{tabular}{|l|} 
POM1106 \\
\end{tabular} & $2 \mathrm{~A}$ & 0.0 & 12.0 & 20.0 & 27.5 & 87.6 & 87.6 & 19.9 & 10.2 & 51.5 & 8.5 & 7.8 & & & & -1.6 & 4.5 & -0.4 & 6.0 & 5.8 & 0.85 & 0.00 & 4.66 & 0.08 & 0.72 \\
\hline \begin{tabular}{|l|} 
POM1141 \\
\end{tabular} & $2 \mathrm{~A}$ & 0.0 & 22.3 & 31.2 & 39.2 & 461.4 & 461.4 & 31.5 & 13.0 & 41.3 & 9.7 & 8.5 & & & & 10.7 & 11.2 & 1.0 & 13.4 & 8.2 & 0.66 & 0.00 & 0.42 & 0.12 & 0.58 \\
\hline Intra-model POM & $2 \mathrm{~A}$ & 0.0 & 13.9 & 22.9 & 32.4 & 251.9 & 251.9 & 23.6 & 13.0 & 55.2 & 10.4 & 9.2 & 53.4 & 7.4 & 30.9 & 2.1 & 4.5 & 0.5 & 6.4 & 6.0 & 0.83 & 0.00 & 2.03 & 0.10 & 0.69 \\
\hline T400 & $2 \mathrm{~B}$ & 2.7 & 12.0 & 19.6 & 30.4 & 50.4 & 47.7 & 21.0 & 10.8 & 51.5 & 9.4 & 9.0 & & & & & & & & & & & & & \\
\hline \begin{tabular}{|l|} 
POM1105 \\
\end{tabular} & $2 \mathrm{~B}$ & 0.0 & 8.5 & 15.9 & 23.8 & \begin{tabular}{|l|}
69.2 \\
\end{tabular} & 69.2 & 17.0 & 10.5 & 61.6 & 8.7 & 7.6 & & & & -3.7 & 5.3 & -0.7 & 6.6 & 5.5 & 0.86 & 0.00 & 6.00 & 0.07 & 0.75 \\
\hline \begin{tabular}{|l|} 
POM1106 \\
\end{tabular} & $2 \mathrm{~B}$ & 0.0 & 8.5 & 17.0 & 25.0 & 59.2 & 59.2 & 17.8 & 10.7 & 60.0 & 9.0 & 8.3 & & & & -2.3 & 4.3 & -0.5 & 5.7 & 5.2 & 0.87 & 0.00 & 4.65 & 0.07 & 0.79 \\
\hline \begin{tabular}{|l|} 
POM1141 \\
\end{tabular} & 2B & 1.1 & 19.4 & 28.1 & 36.3 & 74.7 & 73.6 & 28.5 & 11.7 & 40.9 & 9.7 & 8.5 & & & & 8.9 & 9.1 & 1.0 & 10.2 & 5.1 & 0.85 & 0.00 & -4.49 & 0.09 & 0.80 \\
\hline \begin{tabular}{|l|} 
Intra-model POM \\
\end{tabular} & $2 \mathrm{~B}$ & 0.0 & 11.4 & 20.7 & 30.2 & 72.4 & 72.4 & 21.4 & 12.2 & 57.3 & 10.1 & 9.4 & 55.4 & 6.9 & 31.2 & 0.9 & 3.4 & 0.3 & 4.6 & 4.5 & 0.92 & 0.00 & 0.77 & 0.08 & 0.82 \\
\hline T400 & $3 \mathrm{~A}$ & 2.7 & 13.6 & 24.7 & 32.9 & 67.7 & 65.0 & 23.8 & 11.7 & 49.3 & 10.1 & 9.4 & & & & & & & & & & & & & \\
\hline \begin{tabular}{|l|} 
POM1105 \\
\end{tabular} & $3 \mathrm{~A}$ & 0.0 & 14.7 & 26.1 & 37.1 & 319.3 & 319.3 & 30.2 & 24.8 & 82.1 & 16.2 & 11.2 & & & & 7.4 & 16.4 & 0.4 & 28.0 & 27.0 & 0.07 & 0.00 & 23.02 & 0.13 & 0.03 \\
\hline \begin{tabular}{|l|} 
POM1106 \\
\end{tabular} & $3 \mathrm{~A}$ & 0.0 & 12.4 & 22.9 & 30.2 & 254.3 & 254.3 & 22.2 & 12.6 & 56.7 & 9.9 & 8.6 & & & & -0.9 & 5.0 & -0.2 & 7.4 & 7.3 & 0.76 & 0.00 & 6.35 & 0.10 & 0.65 \\
\hline \begin{tabular}{|l|} 
POM1141 \\
\end{tabular} & $3 \mathrm{~A}$ & 0.0 & 21.3 & 33.2 & 40.9 & 244.3 & 244.3 & 32.2 & 13.7 & 42.6 & 10.9 & 9.6 & & & & 9.6 & 10.5 & 0.9 & 13.3 & 9.1 & 0.64 & 0.00 & 2.37 & 0.15 & 0.54 \\
\hline \begin{tabular}{|l|} 
Intra-model POM \\
\end{tabular} & $3 \mathrm{~A}$ & 0.0 & 17.4 & 27.3 & 36.5 & 254.3 & 254.3 & 27.3 & 14.1 & 51.7 & 11.0 & 9.5 & 37.6 & NA & NA & 4.4 & 6.0 & 0.7 & 8.5 & 7.3 & 0.76 & 0.00 & 2.15 & 0.13 & 0.64 \\
\hline T400 & 3B & 2.7 & 14.6 & 23.2 & 32.5 & 54.7 & 52.0 & 23.4 & 11.5 & 49.2 & 9.6 & 8.9 & & & & & & & & & & & & & \\
\hline \begin{tabular}{|l|} 
POM1105 \\
\end{tabular} & $3 \mathrm{~B}$ & 0.0 & 14.3 & 25.4 & 36.4 & 306.0 & 306.0 & 29.4 & 24.2 & 82.4 & 15.6 & 11.1 & & & & 7.9 & 15.6 & 0.5 & 28.1 & 27.0 & 0.05 & 0.00 & 22.65 & 0.14 & 0.01 \\
\hline POM1106 & $3 \mathrm{~B}$ & 0.0 & 13.1 & 21.6 & 30.1 & 102.3 & 102.3 & 21.7 & 12.0 & 55.0 & 9.6 & 8.5 & & & & -1.1 & 4.8 & -0.2 & 6.8 & 6.7 & 0.79 & 0.00 & 5.68 & 0.09 & 0.70 \\
\hline \begin{tabular}{|l|} 
POM1141 \\
\end{tabular} & 3B & 0.0 & 21.7 & 31.3 & 40.5 & 122.7 & 122.7 & 31.3 & 13.7 & 43.8 & 10.8 & 9.4 & & & & 9.9 & 10.6 & 0.9 & 13.4 & 9.1 & 0.63 & 0.00 & 1.92 & 0.14 & 0.56 \\
\hline \begin{tabular}{|l|} 
Intra-model POM \\
\end{tabular} & 3B & 0.0 & 15.9 & 26.2 & 34.9 & 116.8 & 116.8 & 26.2 & 14.1 & 53.8 & 11.2 & 9.6 & 38.6 & NA & NA & 4.4 & 5.9 & 0.8 & 8.2 & 6.9 & 0.77 & 0.00 & 1.80 & 0.12 & 0.68 \\
\hline T400 & $3 \mathrm{C}$ & 2.7 & 13.5 & 24.4 & 33.1 & 53.1 & 50.4 & 23.4 & 11.3 & 48.3 & 9.8 & 9.6 & & & & & & & & & & & & & \\
\hline \begin{tabular}{|l|} 
POM1105 \\
\end{tabular} & $3 \mathrm{C}$ & 0.0 & 17.2 & 29.7 & 51.7 & 604.6 & 604.6 & 42.9 & 43.8 & 102.0 & 29.2 & 14.6 & & & & 24.5 & 31.8 & 0.8 & 53.9 & 48.0 & 0.02 & 0.00 & 22.03 & 0.12 & 0.01 \\
\hline \begin{tabular}{|l|} 
POM1106 \\
\end{tabular} & $3 \mathrm{C}$ & 0.0 & 12.9 & 22.7 & 31.3 & 145.5 & 145.5 & 22.2 & 11.8 & 53.1 & 9.8 & 9.2 & & & & -0.2 & 4.3 & -0.1 & 6.6 & 6.6 & 0.80 & 0.00 & 4.56 & 0.08 & 0.71 \\
\hline \begin{tabular}{|l|} 
POM1141 \\
\end{tabular} & $3 \mathrm{C}$ & 0.0 & 22.0 & 31.1 & 41.2 & 131.7 & 131.7 & 32.1 & 13.4 & 41.9 & 10.5 & 9.5 & & & & 9.6 & 10.5 & 0.9 & 13.3 & 9.2 & 0.61 & 0.00 & 2.47 & 0.12 & 0.55 \\
\hline Intra-model POM & $3 \mathrm{C}$ & 0.0 & 16.2 & 25.5 & 34.7 & 145.5 & 145.5 & 26.2 & 13.9 & 53.2 & 10.9 & 9.3 & 37.1 & NA & NA & 4.7 & 5.9 & 0.8 & 8.1 & 6.5 & 0.80 & 0.00 & 0.65 & 0.10 & 0.71 \\
\hline
\end{tabular}

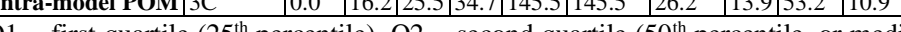

\begin{tabular}{l|l|l|l|l}
37.1 & NA \\
\hline
\end{tabular}

NA

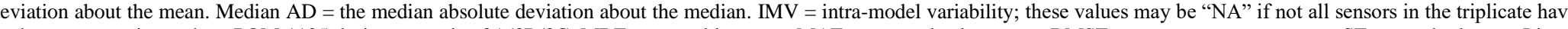
regression parameters relate the prediction of reference analyzer measurements (dependent variable) by LCS measurements (independent variable)
. 


\section{Example PM LCS Additional Details}

\subsection{Sensor and Data Information}

The PurpleAir PA-II test units contained two Plantower PMS5003 optical particle sensors. Plantower does not explicitly specify whether these sensors were optical particle counters (measuring single particle scattering; based on Mie theory) or nephelometers (measuring ensemble particle scattering; based on Beer-Lambert law). The manufacturer specification sheet for the Plantower PMS5003 sensor mentions "Mie theory", leading many investigators to initially assume that these sensors are optical particle counters [7]. However, emerging research suggests that the response of Plantower PMS5003 sensors is more consistent with that exhibited by nephelometers $[8,9]$.

Since most PM LCS only have one particle sensor, they report only one $\mathrm{PM}_{2.5}$ value, so there is no ambiguity to the user about what the LCS perceives is the $\mathrm{PM}_{2.5}$ concentration. In contrast, the PurpleAir PA-II units reported data from two Plantower PMS5003 sensors (referred to as "Channel A" and "Channel B"). The PurpleAir data platform logs the $\mathrm{PM}_{2.5}$ values from Channel A and Channel B separately, and the PurpleAir data platform does not average or otherwise merge measurements from Channel A and Channel B into a single $\mathrm{PM}_{2.5}$ value.

In executing the evaluation protocol in this work, the decision was made for this example evaluation case to only consider the $\mathrm{PM}_{2.5}$ values from Channel A. Figure S11a shows the distribution profile of all concentrations collected in this study, which appears to be very similar between both channels. Figure S11b shows the linear regression between both channels; though the slope is near unity and the intercept is less than $1 \mu \mathrm{g} / \mathrm{m}^{3}$, there appears to be a $\sim 4 \%$ underreporting of concentrations by Channel A compared to Channel B. Thus, if the average of Channel A and B were used in this analysis, some of the evaluation results may have been $\sim 2 \%$ higher compared to using Channel A alone. Because the differences between Channels A and B are small, the general conclusions drawn from the execution of this evaluation protocol using the PurpleAir PA-II LCS as an example would not have changed, regardless of whether Channel A, Channel B, or the average of both channels was used for the data analysis.
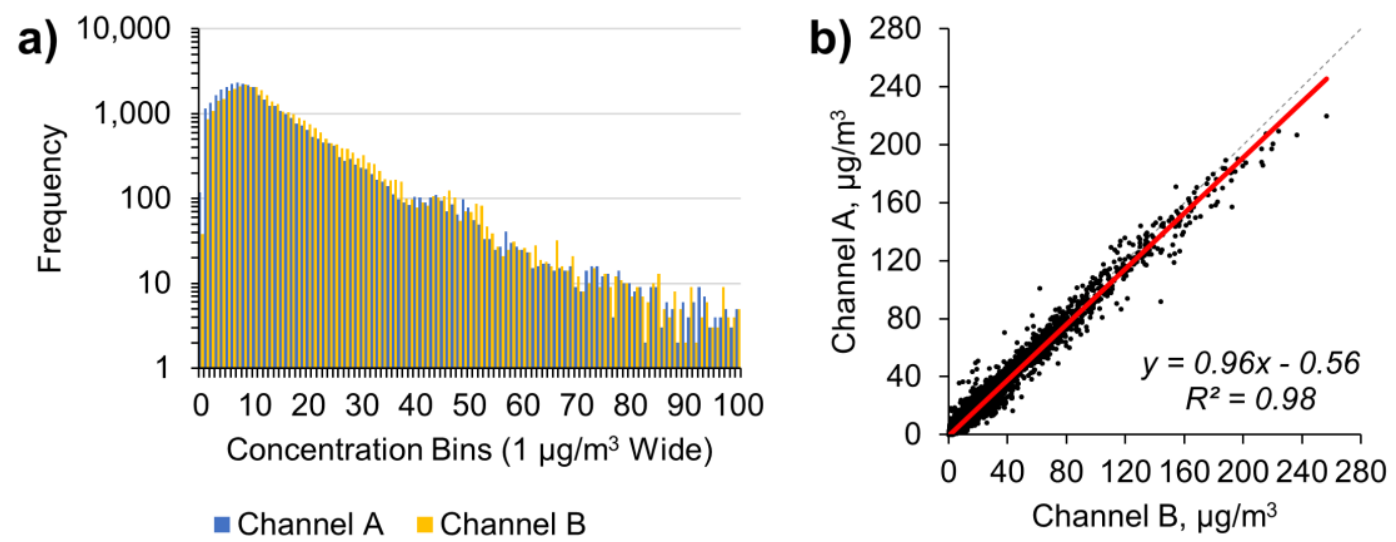

Figure S11: Comparison of $\mathrm{PM}_{2.5}$ concentrations collected by PurpleAir PA-II Channels A and B across all test scenarios and from all three LCS units $(\mathrm{n}=36,807)$. a) Histogram of concentrations reported by both channels. The concentration bin range is truncated at $100 \mu \mathrm{g} / \mathrm{m}^{3}$ since concentration frequencies become vanishingly small beyond that value. b) Scatterplot of paired Channel A and B values. The dashed line is the one-to-one line, and the red line is the linear regression model. The standard error of the slope is \pm 0.0007 and the standard error of the intercept is \pm 0.014 . 
In addition, each Plantower PMS5003 sensor reports two values of $\mathrm{PM}_{2.5}$ : one labeled " $\mathrm{CF}=1$ " to mean no atmospheric correction factor is applied and that this is the value to be used for indoor environments, and the second labeled " $\mathrm{CF}=\mathrm{ATM}$ " to mean an atmospheric correction factor (that is unknown and proprietary) is applied and that this is the value to be used for outdoor environments. For all analyses in this work, data with the CF=ATM correction factor were used.

PurpleAir initially reversed the labels on the data columns for the two correction factors; in data files downloaded prior to October 20, 2019 the columns labeled $\mathrm{CF}=1$ are actually $\mathrm{CF}=\mathrm{ATM}$ and vice versa; and for files downloaded after October 20, 2019 the columns are correctly labeled. Our $R$ data processing scripts automatically handled the labelling issue by 1 ) using an $R$ function to extract a PA-II data file's creation date and then 2) determining if the file creation date was before or after October 20, 2019. If the file creation date was before October 20, 2019, the $R$ script would relabel $\mathrm{CF}=1$ columns as $\mathrm{CF}=\mathrm{ATM}$, and vice versa. If the file creation date was after October 20, 2019 , the $R$ script took no relabeling actions.

\subsection{Wind Speed Effects in Stationary Deployment}

Unrelated work performed by the AQ-SPEC group investigated stationary PurpleAir PA-II performance issues in California communities that regularly experience high winds. It was observed in both an inland desert community and a coastal community that there was a distinct shift in correlation between $\mathrm{PM}_{2.5}$ concentrations reported by PA-II units and regulatory reference monitors when hourly average wind speeds exceeded roughly 8 miles per hour, or $3.6 \mathrm{~m} / \mathrm{s}$ (Figure S12). Below this wind speed the PA-II units showed a near-unity relationship with reference monitors, but above this wind speed the PA-II units underestimated $\mathrm{PM}_{2.5}$ by a factor of about 5 to 6. Since this phenomenon was observed in two different environments, it is possible that PA-II underestimation in high winds may be related to mechanical limitations of the unit (since the sample is aspired into the device using a small fan).

In contrast, the Scenario 3 mobile performance results in this study showed that the PurpleAir PAII devices tended to overestimate $\mathrm{PM}_{2.5}$ with increasing GBMP velocity. Future research is planned to investigate why different phenomena are observed in mobile and stationary deployment applications.

a)

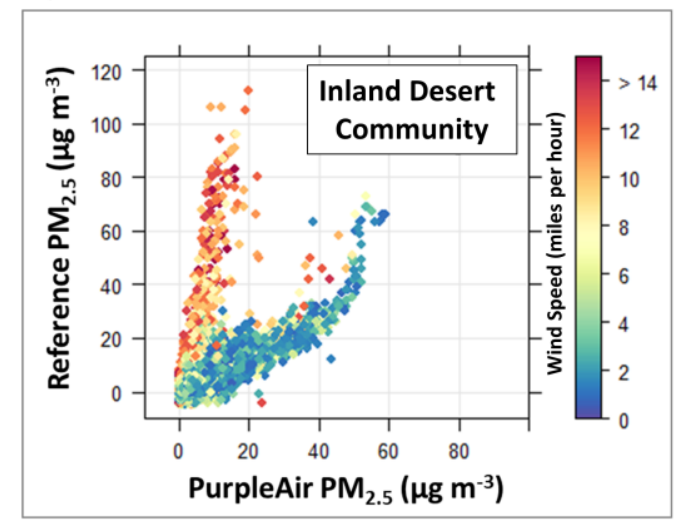

b)

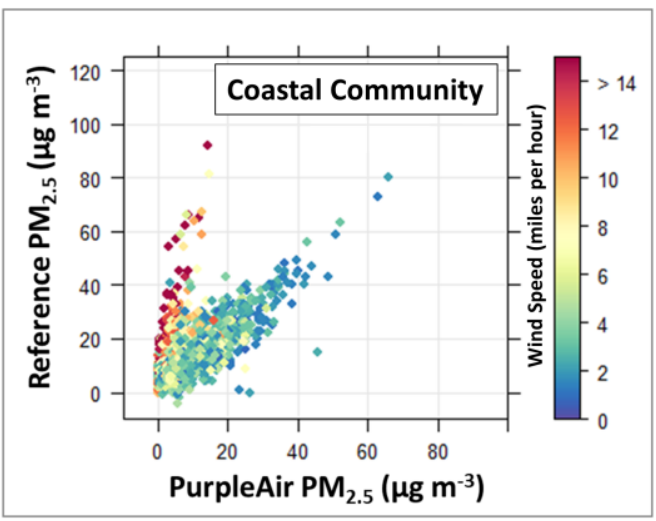

Figure S12: Stationary hourly-averaged $\mathrm{PM}_{2.5}$ measurements of a regulatory reference monitor and a PurpleAir PA-II sensor unit for a) an inland desert community in California and b) a coastal community in California. Observations are colored by hourly-averaged wind speeds. 


\subsection{Preliminary Scenario 2 Results to Identify Optimal Position Inside Rooftop Box}

The acquired data set for the paired reference analyzer and sensors during preliminary Scenario 2 testing (sensors placed equidistantly across the box width, with each unit taking turns in each position) was used to calculate regression models for each unit in each position in the box. The position resulting in the highest $\mathrm{R}^{2}$ and regression slopes nearest unity were determined to be the optimal placement location for that LCS in the box for Scenario 2 testing. An example preliminary Scenario 2 result for a PM sensor is shown in Figure S13.

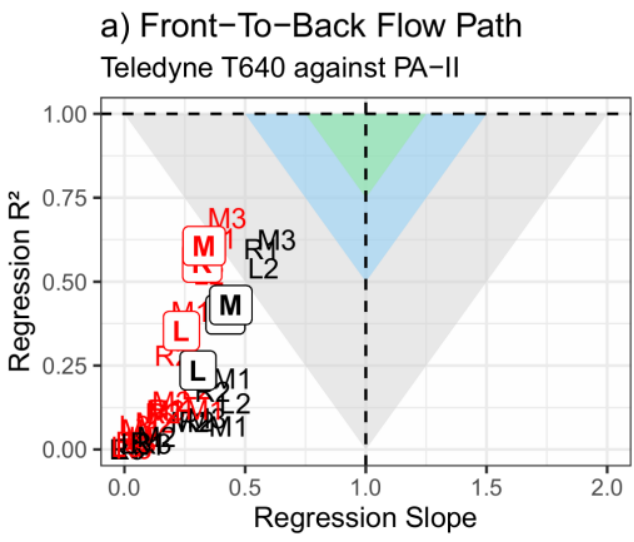

a PM2.5 a PM10

c) Top-To-Back Flow Path

Teledyne T640 against PA-II

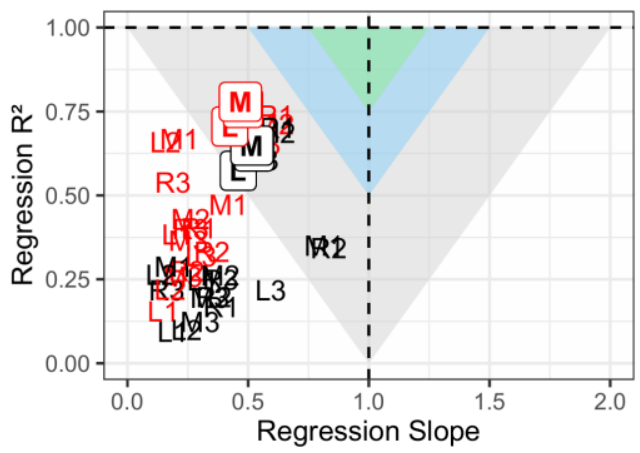

a PM2.5 a PM10 b) Front-To-Back Flow Path GRIMM 11-D against PA-II

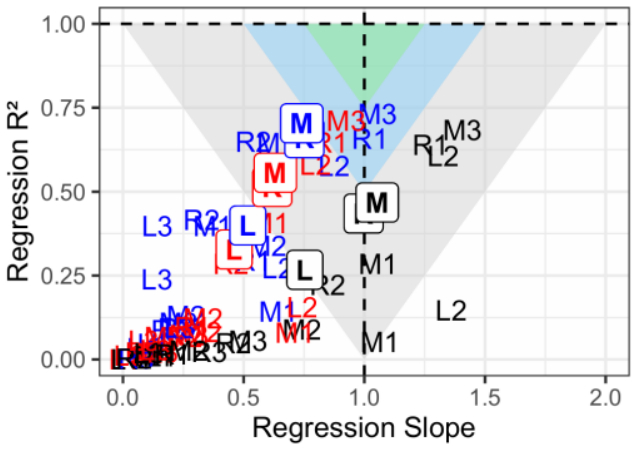

a PM1.0 a PM2.5 a PM10

d) Top-To-Back Flow Path GRIMM 11-D against PA-II

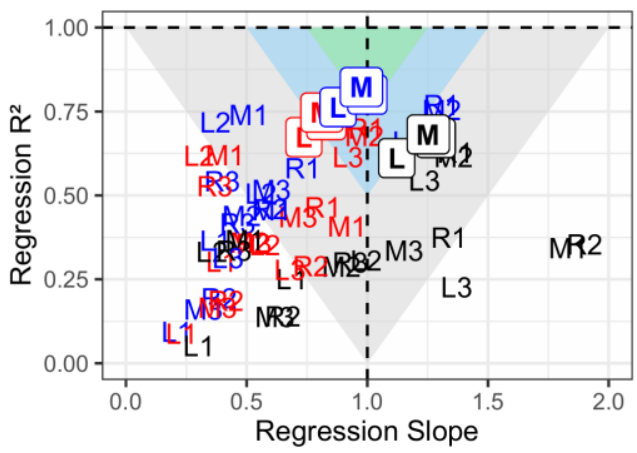

a PM1.0 a PM2.5 a PM10

Figure S13: Example results from Preliminary Scenario 2 testing for a PM sensor (PA-II) LCS when a) the box had a front-to-back flow (FTB) configuration and LCS measurements were compared to the Teledyne T640, b) the box had an FTB configuration and LCS measurements were compared to the GRIMM 11-D, c) the box had a top-to-back (TTB) configuration and LCS measurements were compared to the Teledyne T640, and d) the box had a TTB configuration and LCS measurements were compared to the GRIMM 11-D. Letter-number labels denote an individual test correlation result for an LCS of the triplicate set $(1,2$, or 3$)$ in a given position in the rooftop box when facing the direction of travel $(\mathrm{L}=$ left, $\mathrm{M}=$ middle, or $\mathrm{R}=$ right); for example, "L3" indicates a test result for the third LCS of the triplicate when installed in the left position of the box, directly in the ambient air flow path. Letter-only labels denote the aggregated correlation result for all LCS of the triplicate set installed in each position in the rooftop box. Shaded regions are to assist the eye, and do not represent performance criteria. 


\subsection{Individual Sensor Unit Evaluation Results}

The correlation plots of each PA-II unit compared to the reference analyzer for each test scenario is shown in Figure S14. Summary statistics of the reference analyzer and each PA-II unit, for every test scenario, are listed in Table S4. 
a) Scenario 1

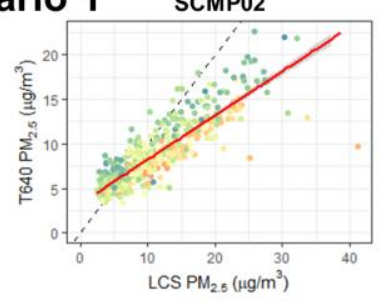

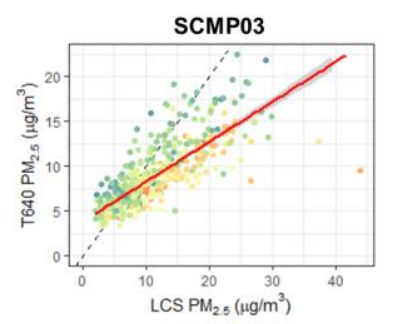

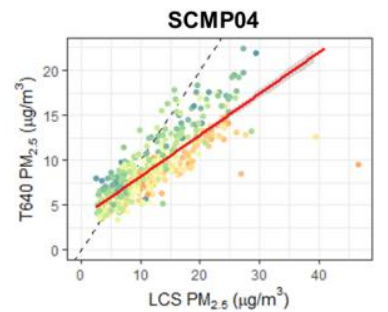

b) Scenario 2A (Front-To-Back Flow Path)
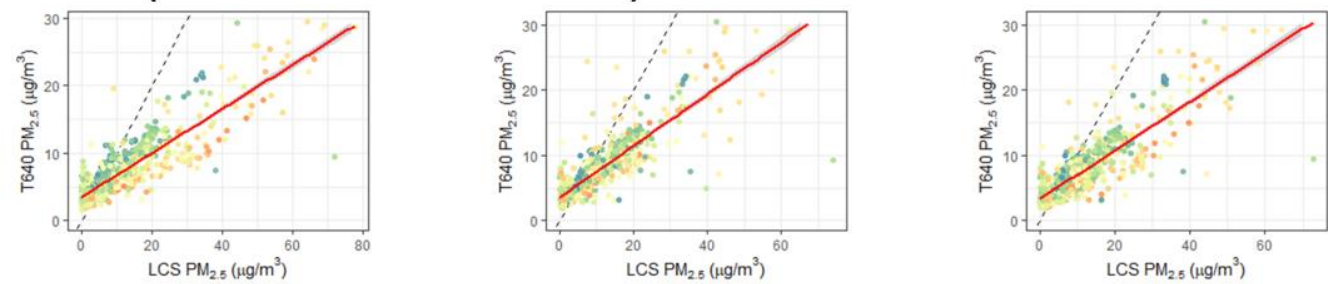

c) Scenario 2B (Top-To-Back Flow Path)
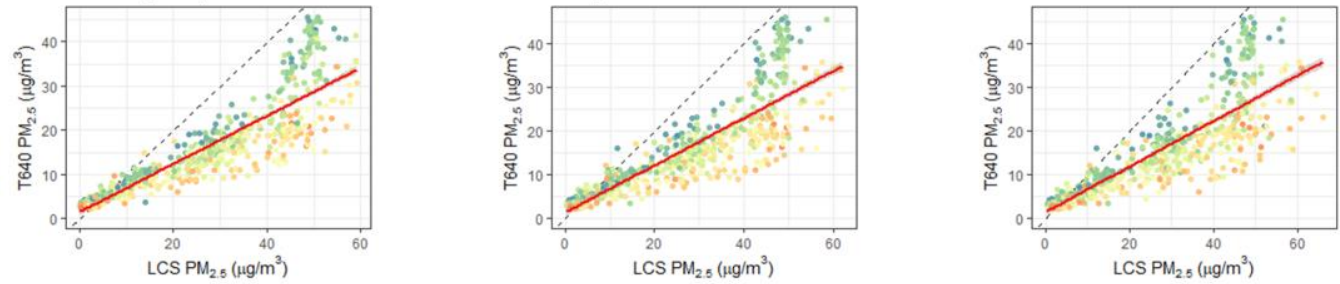

d) Scenario 3A (Inlet Facing "Default" Direction)
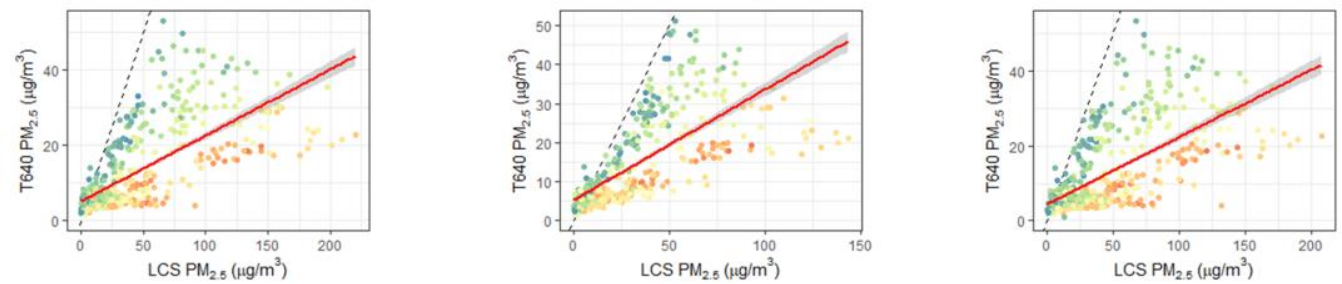

e) Scenario 3B (Inlet Facing Forward)
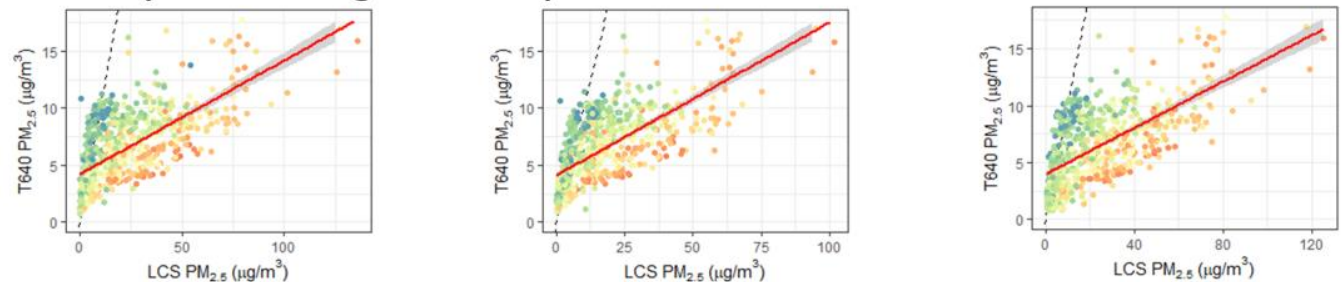

f) Scenario 3B (Inlet Facing Backward)
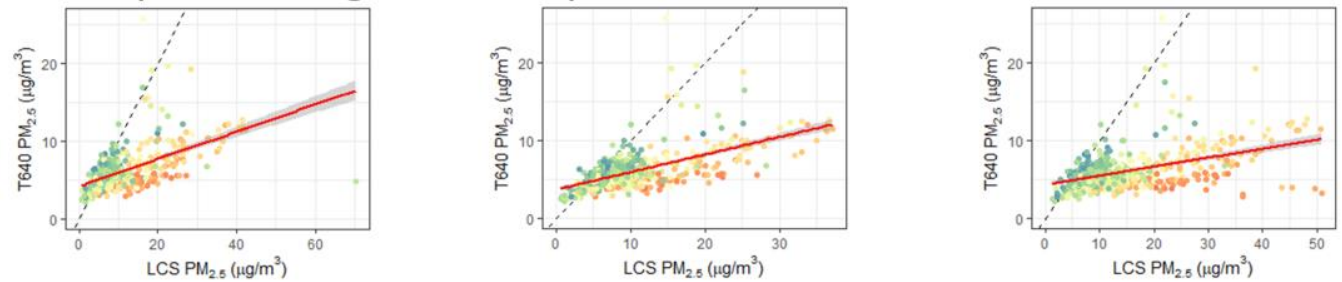

Figure S14: Correlation plots for the intra-unit $\mathrm{PM}_{2.5}$ measurement values for the triplicate set of PA-II LCS units for each test scenario, with points colored by GBMP velocity. The dashed black line is the one-to-one line, the red line represents a linear regression mode, and the gray shaded area is the $95 \%$ confidence interval of the model (which may not be broad enough to be visible in all plots). 
Table S4: Summary statistics for the example $\mathrm{PM}_{2.5}$ sensor (PA-II) evaluation in every test scenario, including those for the reference analyzer (T640), individual sensor units (intra-unit), and the sensor units as a group (intra-model)

\begin{tabular}{|c|c|c|c|c|c|c|c|c|c|c|c|c|c|c|c|c|c|c|c|c|c|c|c|c|c|}
\hline Unit & Scenario & $\begin{array}{l}\text { Min, } \\
\mu \mathrm{g} / \mathrm{m}^{3}\end{array}$ & $\begin{array}{l}\mathrm{Q1}, \\
\mu \mathrm{g} / \mathrm{m}^{3}\end{array}$ & $\begin{array}{l}\mathrm{Q} 2, \\
\mu \mathrm{g} / \mathrm{m}^{3}\end{array}$ & $\left|\begin{array}{l}\mathbf{Q 3}, \\
\mu \mathrm{g} / \mathrm{m}^{3}\end{array}\right|$ & \begin{tabular}{|l|}
$\mathbf{M a x}$, \\
$\mathbf{\mu g} / \mathbf{m}^{3}$
\end{tabular} & $\mid \begin{array}{l}\text { Range, } \\
\mu \mathrm{gg} / \mathrm{m}^{3}\end{array}$ & $\prod_{\mu \mathrm{g} / \mathrm{m}^{3}}^{\text {Mean, }}$ & $\left\{\begin{array}{l}\mathrm{SD}, \\
\boldsymbol{\mu g} / \mathbf{m}^{3}\end{array}\right.$ & \begin{tabular}{|l|l|}
$\mathbf{R S S D}$, \\
$\boldsymbol{\mu g} / \mathbf{m}^{3}$
\end{tabular} & $\begin{array}{l}\text { Mean } \\
\mathrm{AD}, \\
\mu \mathrm{g} / \mathrm{m}^{3}\end{array}$ & \begin{tabular}{|l} 
Median \\
$\mathrm{AD}$, \\
$\mu \mathrm{g} / \mathrm{m}^{3}$
\end{tabular} & $\begin{array}{l}\text { IMV } \\
\text { (Range), } \\
\%\end{array}$ &, $\begin{array}{l}\text { IMV } \\
\text { (Absolute), } \\
\mu \mathrm{gg} / \mathbf{m}^{3}\end{array}$ & \begin{tabular}{|l|} 
IMV \\
(Relative), \\
$\%$
\end{tabular} & \begin{tabular}{|l} 
MBE, \\
$\mu \mathrm{gg} / \mathrm{m}^{3}$
\end{tabular} & $\begin{array}{l}\text { MAE, } \\
\mathbf{\mu g} / \mathbf{m}^{3}\end{array}$ & \begin{tabular}{|l} 
MBE/ \\
MAE
\end{tabular} & $\begin{array}{l}\text { RMSE, } \\
\mu \mathrm{g} / \mathrm{m}^{3}\end{array}$ & $\begin{array}{l}\text { Residual } \\
\text { SD, } \\
\mathbf{\mu g} / \mathbf{m}^{3}\end{array}$ & Slope & \begin{tabular}{|l} 
Slope \\
SE
\end{tabular} & \begin{tabular}{|l|l|} 
e Intercept
\end{tabular} & $\begin{array}{l}\text { Intercept } \\
\text { SE }\end{array}$ & $\mathbf{R}^{2}$ \\
\hline T640 & 1 & 3.1 & 6.4 & 8.1 & 11.0 & 25.3 & 22.2 & 9.4 & 4.3 & 46.3 & 3.3 & 1.9 & & & & & & & & & & & & & \\
\hline \begin{tabular}{|l|} 
SCMP02 \\
\end{tabular} & 1 & 2.4 & 6.9 & 9.4 & 14.5 & 41.1 & 38.7 & 11.7 & 7.0 & 59.9 & 5.4 & 3.6 & & & & 2.1 & 2.8 & 0.7 & 4.0 & 3.5 & 0.49 & 0.01 & 3.33 & 0.15 & 0.75 \\
\hline SCMP03 & 1 & 2.0 & 6.8 & 9.4 & 14.7 & 43.8 & 41.8 & 11.5 & 6.8 & 58.9 & 5.3 & 3.5 & & & & 2.1 & 3.0 & 0.7 & 4.4 & 3.9 & 0.45 & 0.01 & 3.82 & 0.17 & 0.63 \\
\hline SCMP04 & 1 & 2.6 & 6.8 & 9.8 & 15.3 & 46.4 & 43.8 & 11.8 & 6.8 & 57.7 & 5.4 & 3.7 & & & & 2.3 & 3.0 & 0.8 & 4.4 & 3.8 & 0.46 & 0.01 & 3.53 & 0.16 & 0.69 \\
\hline \begin{tabular}{|l|} 
Intramodel PA-II \\
\end{tabular} & 1 & 2.0 & 6.4 & 9.0 & 13.6 & 46.4 & 44.5 & 10.6 & 6.0 & 56.4 & 4.7 & 3.5 & 3.9 & 0.2 & 1.9 & 2.1 & 2.5 & 0.8 & 3.8 & 3.2 & 0.51 & 0.01 & 3.10 & 0.12 & 0.82 \\
\hline T640 & $2 \mathrm{~A}$ & 0.5 & 3.6 & 5.1 & 8.6 & 40.5 & 40.0 & 7.1 & 5.7 & 81.1 & 3.9 & 1.9 & & & & & & & & & & & & & \\
\hline SCMP02 & $2 \mathrm{~A}$ & 0.0 & 1.6 & 4.8 & 13.9 & 77.5 & 77.5 & 9.9 & 12.6 & 127.8 & 9.1 & 3.8 & & & & 3.4 & 5.4 & 0.6 & 9.3 & 8.7 & 0.33 & 0.01 & 3.45 & 0.10 & 0.78 \\
\hline SCMP03 & $2 \mathrm{~A}$ & 0.0 & 1.2 & 4.4 & 11.5 & 73.9 & 73.9 & 8.3 & 10.5 & 126.3 & 7.6 & 3.5 & & & & 1.7 & 4.1 & 0.4 & 6.8 & 6.6 & 0.39 & 0.01 & 3.54 & 0.11 & 0.74 \\
\hline SCMP04 & $2 \mathrm{~A}$ & 0.0 & 1.8 & 5.2 & 13.0 & 72.7 & 72.7 & 9.2 & 11.0 & 118.9 & 8.1 & 4.0 & & & & 2.7 & 4.7 & 0.6 & 7.7 & 7.2 & 0.37 & 0.01 & 3.32 & 0.11 & 0.74 \\
\hline \begin{tabular}{|l|} 
Intramodel PA-II \\
\end{tabular} & $2 \mathrm{~A}$ & 0.0 & 1.5 & 5.0 & 13.0 & 77.5 & 77.5 & 9.1 & 11.2 & 123.4 & 8.1 & 4.0 & 19.7 & 1.0 & 10.4 & 2.5 & 4.5 & 0.5 & 7.5 & 7.1 & 0.38 & 0.01 & 3.22 & 0.09 & 0.83 \\
\hline T640 & $2 \mathrm{~B}$ & 0.8 & 7.0 & 13.5 & 21.6 & 51.7 & 51.0 & 16.0 & 11.4 & 70.9 & 9.1 & 7.2 & & & & & & & & & & & & & \\
\hline SCMP02 & $2 \mathrm{~B}$ & 0.1 & 9.8 & 26.1 & 42.1 & 60.1 & 60.1 & 25.5 & 17.3 & 67.6 & 14.9 & 16.3 & & & & 10.1 & 10.7 & 0.9 & 13.8 & 9.4 & 0.54 & 0.01 & 1.51 & 0.37 & 0.78 \\
\hline SCMP03 & $2 \mathrm{~B}$ & 0.1 & 10.3 & 26.7 & 42.3 & 62.0 & 61.9 & 25.8 & 16.9 & 65.5 & 14.6 & 16.0 & & & & 10.5 & 11.1 & 1.0 & 14.3 & 9.7 & 0.54 & 0.01 & 1.46 & 0.41 & 0.73 \\
\hline SCMP04 & $2 \mathrm{~B}$ & 0.2 & 11.4 & 27.5 & 42.5 & 65.9 & 65.7 & 26.5 & 17.0 & 64.2 & 14.6 & 15.7 & & & & 11.2 & 11.7 & 1.0 & 15.2 & 10.2 & 0.52 & 0.01 & 1.52 & 0.44 & 0.70 \\
\hline \begin{tabular}{|l|} 
Intramodel PA-II \\
\end{tabular} & $2 \mathrm{~B}$ & 0.1 & 9.8 & 26.8 & 43.0 & 65.9 & 65.8 & 26.1 & 17.4 & 66.7 & 15.2 & 16.5 & 4.6 & 0.6 & 2.4 & 10.7 & 11.1 & 1.0 & 14.3 & 9.5 & 0.54 & 0.01 & 1.22 & 0.39 & 0.76 \\
\hline T640 & $3 \mathrm{~A}$ & 0.5 & 4.7 & 6.5 & 13.6 & 83.3 & 82.8 & 11.5 & 11.4 & 98.7 & 8.5 & 2.4 & & & & & & & & & & & & & \\
\hline SCMP02 & $3 \mathrm{~A}$ & 0.1 & 5.4 & 16.1 & 45.3 & 219.6 & 219.6 & 34.2 & 42.7 & 124.9 & 31.8 & 12.5 & & & & 22.8 & 23.7 & 1.0 & 41.5 & 34.7 & 0.17 & 0.01 & 5.10 & 0.34 & 0.53 \\
\hline SCMP03 & $3 \mathrm{~A}$ & 0.1 & 4.0 & 10.8 & 39.8 & 143.4 & 143.3 & 24.8 & 28.6 & 115.2 & 22.6 & 9.0 & & & & 12.2 & 13.7 & 0.9 & 24.2 & 21.0 & 0.28 & 0.01 & 5.26 & 0.39 & 0.55 \\
\hline SCMP04 & $3 \mathrm{~A}$ & 0.0 & 8.1 & 21.5 & 49.4 & 207.7 & 207.7 & 36.2 & 38.9 & 107.6 & 29.4 & 15.6 & & & & 25.7 & 26.0 & 1.0 & 40.8 & 31.8 & 0.18 & 0.01 & 4.40 & 0.39 & 0.46 \\
\hline \begin{tabular}{|l|} 
Intramodel PA-II \\
\end{tabular} & $3 \mathrm{~A}$ & 0.0 & 6.0 & 18.1 & 43.8 & 214.5 & 214.4 & 33.3 & 38.7 & 116.4 & 28.6 & 14.0 & 37.9 & 7.1 & 21.8 & 19.0 & 19.9 & 1.0 & 34.5 & 28.7 & 0.21 & 0.01 & 4.95 & 0.38 & 0.55 \\
\hline T640 & 3B & 0.4 & 3.7 & 6.0 & 9.0 & 20.8 & 20.4 & 6.5 & 3.6 & 54.9 & 2.9 & 2.6 & & & & & & & & & & & & & \\
\hline SCMP02 & 3B & 0.1 & 3.5 & 13.2 & 28.6 & 135.7 & 135.6 & 19.4 & 20.9 & 107.5 & 15.8 & 10.6 & & & & 15.1 & 15.9 & 1.0 & 24.9 & 19.7 & 0.10 & 0.00 & 4.19 & 0.13 & 0.44 \\
\hline SCMP03 & 3B & 0.0 & 3.0 & 11.6 & 21.8 & 101.5 & 101.5 & 15.5 & 16.1 & 103.3 & 12.0 & 9.0 & & & & 10.5 & 11.4 & 0.9 & 18.1 & 14.7 & 0.13 & 0.01 & 4.11 & 0.13 & 0.48 \\
\hline \begin{tabular}{|l|} 
SCMP04 \\
\end{tabular} & 3B & 0.2 & 5.2 & 14.2 & 29.5 & 125.1 & 124.9 & 20.2 & 19.8 & 98.0 & 15.1 & 10.1 & & & & 15.9 & 16.4 & 1.0 & 24.5 & 18.7 & 0.10 & 0.00 & 3.99 & 0.14 & 0.41 \\
\hline \begin{tabular}{|l|} 
Intramodel PA-II \\
\end{tabular} & $3 B$ & 0.0 & 4.6 & 13.8 & 29.9 & 135.7 & 135.6 & 20.0 & 20.0 & 99.9 & 15.4 & 10.5 & 26.8 & 3.0 & 14.8 & 13.8 & 14.4 & 1.0 & 22.4 & 17.6 & 0.11 & 0.00 & 4.02 & 0.13 & 0.46 \\
\hline T640 & $3 \mathrm{C}$ & 1.2 & 4.5 & 5.6 & 6.9 & 34.5 & 33.3 & 6.0 & 2.5 & 41.3 & 1.7 & 1.2 & & & & & & & & & & & & & \\
\hline SCMP02 & $3 \mathrm{C}$ & 0.5 & 5.1 & 7.0 & 10.3 & 42.3 & 41.8 & 9.4 & 7.2 & 76.6 & 5.0 & 2.3 & & & & 4.1 & 4.6 & 0.9 & 8.0 & 6.9 & 0.17 & 0.01 & 4.30 & 0.14 & 0.33 \\
\hline \begin{tabular}{|l|} 
SCMP03 \\
\end{tabular} & $3 \mathrm{C}$ & 0.6 & 5.9 & 7.9 & 11.0 & 37.1 & 36.5 & 9.7 & 6.4 & 66.0 & 4.5 & 2.3 & & & & 4.3 & 4.6 & 0.9 & 7.0 & 5.5 & 0.23 & 0.01 & 3.74 & 0.15 & 0.39 \\
\hline SCMP04 & $3 \mathrm{C}$ & 1.0 & 7.3 & 10.2 & 16.4 & 50.8 & 49.8 & 13.4 & 9.3 & 69.4 & 7.0 & 3.8 & & & & 8.6 & 8.7 & 1.0 & 12.3 & 8.7 & 0.12 & 0.01 & 4.38 & 0.17 & 0.20 \\
\hline \begin{tabular}{|l|} 
Intramodel PA-II \\
\end{tabular} & $3 \mathrm{C}$ & 0.5 & 6.3 & 9.0 & 14.4 & 50.8 & 50.3 & 11.7 & 8.3 & 71.1 & 6.2 & 3.3 & 39.3 & 2.6 & 22.1 & 5.6 & 5.8 & 1.0 & 8.7 & 6.6 & 0.18 & 0.01 & 3.94 & 0.15 & 0.33 \\
\hline
\end{tabular}

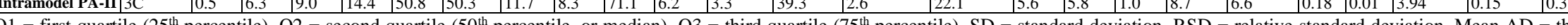
mean absolute deviation about the mean. Median $\mathrm{AD}=$ the median absolute deviation about the median. $\mathrm{IMV}=$ intra-model variability. $\mathrm{MBE}=\mathrm{mean}$ bias error. $\mathrm{MAE}=$ mean absolute error. $\mathrm{RMSE}=$ root-mean-square-error. SE = standard error. Linear regression parameters relate the prediction of reference analyzer measurements (dependent variable) by LCS measurements (independent variable). 


\section{US EPA Federal Reference/Equivalent Methods}

A Federal Reference Method (FRM) is a US EPA approved method or instrument that follows the measurement principles, calibration, and maintenance procedures specified in US Code of Federal Regulations, Title 40, Parts 50 and 53. A Federal Equivalent Method (FEM) is a method or instrument that the US EPA has deemed, under US Code of Federal Regulations, Title 40, Part 53, equivalent to an FRM. The specifications for FRM/FEM designation include requirements such as meeting certain accuracy and reliability criteria, being unaffected by interference from other species in the ambient air, and being capable of deployment in the field by typical air monitoring personnel yet still produce accurate and precise measurements.

It is important to note that while some of the "reference" monitors used on the GBMP have a US EPA FRM/FEM designation, as listed in Table S1, their usage in a GMBP does not mean that the measurements made with these instruments are consistent with FRM/FEM requirements (for reasons such as nonstationary operation and use of different averaging timescales). For example, the $\mathrm{PM}_{2.5}$ reference monitor used on the GBMP logged data every 3 seconds (this high time resolution is better for a moving measurement so that fast-changing conditions can be captured) while this same $\mathrm{PM}_{2.5}$ reference monitor used at a stationary regulatory AMS would report a daily and annual $\mathrm{PM}_{2.5}$ averaged concentration for compliance with regulatory ambient air quality standards.

Even though the use of FRM/FEM instruments on the GBMP are not consistent with some FRM/FEM requirements, such instruments were chosen to serve as GBMP reference monitors because these instruments have an established accuracy and history of valid performance through their US EPA FRM/FEM designations, and this level of verified fidelity made them suitable candidates for use on an otherwise novel and developmental platform. 


\section{References}

[1] P. Baron, "Aerosol calculator," available from pbaron@cdc.gov, 2001.

[2] S.-L. Von Der Weiden, F. Drewnick and S. Borrmann, "Atmospheric Measurement Techniques Particle Loss Calculator-a new software tool for the assessment of the performance of aerosol inlet systems," 2009.

[3] M. Rhudy, "Time Alignment Techniques for Experimental Sensor Data," International Journal of Computer Science \& Engineering Survey, vol. 5, no. 2, pp. 1-14, 2014.

[4] R Core Team, "R: A language and environment for statistical computing," 2019. [Online]. Available: http://www.R-project.org/.

[5] P. J. Brockwell, R. A. Davis and S. E. Fienberg, Time Series: Theory and Methods: Theory and Methods, New York: Springer Science \& Business Media, 1991.

[6] H. W. Borchers, "pracma: Practical Numerical Math Functions," 2019. [Online]. Available: https://CRAN.R-project.org/package=pracma. [Accessed 24 January 2020].

[7] T. Sayahi, A. Butterfield and K. E. Kelly, "Long-term field evaluation of the Plantower PMS low-cost particulate matter sensors," Environmental Pollution, vol. 245, pp. 932-940, 2019.

[8] M. He, N. Kuerbanjiang and S. Dhaniyala, "Performance characteristics of the low-cost Plantower PMS optical sensor," Aerosol Science and Technology, vol. 54, no. 2, pp. 232-241, 2020.

[9] D. H. Hagan and J. H. Kroll, "Assessing the accuracy of low-cost optical particle sensors using a physics-based approach," Atmospheric Measurement Techniques Discussions, pp. 1-36, 2020. 